\title{
Oil and gas platforms with steam bottoming cycles: System integration and
} thermoenvironomic evaluation

Nguyen, Tuong-Van; Tock, Laurence ; Breuhaus, Peter; Marechal, Francois ; Elmegaard, Brian

Published in:

Applied Energy

Link to article, DOI:

10.1016/j.apenergy.2014.06.034

Publication date:

2014

Link back to DTU Orbit

Citation (APA):

Nguyen, T-V., Tock, L., Breuhaus, P., Marechal, F., \& Elmegaard, B. (2014). Oil and gas platforms with steam bottoming cycles: System integration and thermoenvironomic evaluation. Applied Energy, 131, $222-237$. https://doi.org/10.1016/j.apenergy.2014.06.034

\section{General rights}

Copyright and moral rights for the publications made accessible in the public portal are retained by the authors and/or other copyright owners and it is a condition of accessing publications that users recognise and abide by the legal requirements associated with these rights.

- Users may download and print one copy of any publication from the public portal for the purpose of private study or research.

- You may not further distribute the material or use it for any profit-making activity or commercial gain

- You may freely distribute the URL identifying the publication in the public portal 


\title{
Oil and gas platforms with steam bottoming cycles: system integration and thermoenvironomic evaluation
}

\author{
Tuong-Van Nguyen ${ }^{\mathrm{a}, \mathrm{b}, *}$, Laurence Tock $^{\mathrm{b}}$, Peter Breuhaus $^{\mathrm{c}}$, François Maréchal $^{\mathrm{b}}$, Brian Elmegaard $^{\mathrm{a}}$ \\ ${ }^{a}$ Section of Thermal Energy, Department of Mechanical Engineering, Technical University of Denmark, \\ Building 403, Nils Koppels Allé, 2800 Kongens Lyngby, Denmark \\ ${ }^{b}$ Industrial Process and Energy Systems Engineering Laboratory, École Polytechnique Fédérale de Lausanne, \\ Station postale 9, 1015 Lausanne, Switzerland \\ ${ }^{c}$ Department of Energy, International Research Institute of Stavanger, \\ Professor Olav Hanssens vei 15, 4021 Stavanger, Norway
}

\begin{abstract}
The integration of steam bottoming cycles on oil and gas platforms is currently regarded as the most promising option for improving the performance of these energy-intensive systems. In this paper, a North Sea platform is taken as case study, and a systematic analysis of its energy requirements is conducted. The site-scale integration of steam networks is evaluated, based on thermodynamic, economic and environmental performance indicators. The penalties induced by operational restrictions such as (i) the use of a heat transfer loop, (ii) the demand for a heat buffer, (iii) the selection of a specific cooling utility, and (iv) the weight limitations on the platform are quantitatively assessed. The results illustrate the benefits of converting the gas turbine process into a combined cycle, since the fuel gas consumption and the total $\mathrm{CO}_{2}{ }^{-}$ emissions can be reduced by more than $15 \%$. Using the cooling water from the processing plant reveals to be more profitable than using seawater, as the additional pumping power outweighs the benefit of using a cooling medium at a temperature of about $8{ }^{\circ} \mathrm{C}$ lower. This study highlights thereby the importance of analysing energy savings and recovery options at the scale of the entire platform, rather than at the level of the utility plant solely.
\end{abstract}

\section{Introduction}

The extraction of oil and gas from petroleum fields is generally energy-intensive and associated with a significant environmental impact. Offshore oil and gas processing consumes from 10 to several hundreds MW power, depending on the properties of the oil field, the system design set-up, and the export specifications. The combustion of diesel and fuel gas for on-site power generation releases large quantities of $\mathrm{CO}_{2}$ to the atmosphere. Similarly, flaring and venting practices may result in non-negligible $\mathrm{CH}_{4}$-emissions, which are more harmful than $\mathrm{CO}_{2}$-emissions, with regards to the global warming potential. The treatment of the produced water effluents and cooling water can meanwhile lead to a discharge of chemicals such as biocides and methanol to the sea.

These offshore facilities are designed for peak productions of oil and gas [1-4] and they suffer from inherent performance losses, when the hydrocarbon production declines and the water production rises $[5,6]$. The equipments may also be run at different loads, implying that they are not operated at their nominal points.

Although the petroleum throughput decreases, the total power consumption of the facility may increase because of the use of oil recovery techniques, such as water injection, and the operation of several process components at part-load conditions. A possible operational strategy for local power production on offshore

\footnotetext{
*Principal corresponding author. Tel.: +45 4525 4129

Email address: tungu@mek.dtu.dk, tuong-van.nguyen@epfl.ch (Tuong-Van Nguyen)
} 


\begin{tabular}{|c|c|c|c|}
\hline \multicolumn{4}{|c|}{ Nomenclature } \\
\hline I & Environmental impact, $\mathrm{kg} / \mathrm{FU}$ & LCA & Life Cycle Assessment \\
\hline$T$ & Temperature, ${ }^{\circ} \mathrm{C}$ or $\mathrm{K}$ & LCI & Life Cycle Inventory \\
\hline$\dot{Q}$ & Heat rate, $\mathrm{kW}$ & MAETP & Marine Aquatic Eco-Toxicity \\
\hline$\dot{W}$ & Power, kW & MILP & Mixed Integer Linear Programming \\
\hline$\dot{m}$ & Mass flow rate, $\mathrm{kg} / \mathrm{s}$ or $\mathrm{t} / \mathrm{h}$ & MINLP & Mixed Integer Non-Linear Programming \\
\hline$h$ & Specific enthalpy, $\mathrm{kg} / \mathrm{kg}$ & MOO & Multi-Objective Optimisation \\
\hline$p$ & Pressure, bar & NG & Natural gas \\
\hline \multicolumn{2}{|c|}{ Abbreviations } & OE & Exported oil \\
\hline $\mathrm{ACD}$ & Acidification & PART & Partial \\
\hline $\mathrm{CC}$ & Combined cycle & $\mathrm{PR}$ & Peng-Robinson \\
\hline DNA & Dynamic Network Analysis & & \\
\hline EOS & Equation of State & REF & Reference \\
\hline $\mathrm{EQ}$ & Equivalent & \multicolumn{2}{|c|}{ Greek letters } \\
\hline EUT & Eutrophication & $\delta$ & Relative variation, $\%$ \\
\hline FG & Fuel gas & $\eta$ & Energy efficiency, \% \\
\hline FU & Functional Unit & $\rho$ & Pearson's correlation coefficient \\
\hline GE & Exported gas & $\sigma$ & Energy intensity, \% \\
\hline GWP & Global Warming Potential & \multicolumn{2}{|c|}{ Superscripts } \\
\hline INV & Investment & + & Material-/Energy-flow entering the system \\
\hline IPCC & Intergovernmental Panel on Climate Change & - & Material-/Energy-flow leaving the system \\
\hline
\end{tabular}

plants is to share the electric load generation between several but redundant gas turbines, while keeping one on standby. This control strategy allows for a greater operational flexibility and a faster response to possible system failures. However, this results in a lower efficiency of these engines, a larger fuel consumption and greater $\mathrm{CO}_{2}$-emissions. The values of natural gas and of the $\mathrm{CO}_{2}$-tax on the downstream petroleum sector have increased these last years [7-10]. Designing more efficient power generation systems and reducing the fuel consumption have thus gained interest $[11,12]$.

These objectives can be achieved by (i) improving the performance of the processing plant or by (ii) increasing the efficiency of the utility plant. The first possibility has been investigated in a few works [1315]. They revealed, based on detailed energy- and exergy analyses of the oil and gas processing system, several ways to decrease the total power consumption and exergy destruction. These works pinpointed the performance loss sources of such plants, especially in end-life conditions. The exergy destruction in the heat exchangers and the losses associated with the exhaust gases from the power turbines were two of the major sources of the thermodynamic irreversibilities taking place on an oil and gas platform.

The second route has been considered in works that suggested to integrate a bottoming cycle, either to the gas turbines [16-18] or to the processing plant [19]. The integration of steam cycles on oil and gas platforms in the North Sea region is not common, as it is believed that the additional investment costs related to the supplementary weight and space would outweigh the financial gains of exporting a higher amount of gas. However, it may be argued that (i) the steam cycle could replace one of the gas turbines present on-site, (ii) it could be placed on the top of the facility, and that (iii) new steam cycle technologies are more and more compact, and that their weight has been brought down significantly these last years. 
The engineering challenges of installing these power cycles are emphasised in Nord and Bolland [16,17], and a power-to-weight of about 10 tonnes per MW was estimated. For the case studies presented in the works of Kloster et al. [11,12], the integration of a steam cycle was performed as a retrofit option on existing facilities, and the steam cycle was implemented on either one or two gas turbines. The economic benefits were emphasised, as the fuel and $\mathrm{CO}_{2}$-tax costs decreased sharply, while the thermodynamic efficiencies of the retrofitted cycles were greatly enhanced.

Most works focus on possible layouts of the power cycles and on their behaviours at design and off-design conditions, while discussing shortly the heating and power requirements of the oil processing plant. The power cycles are generally regarded separately from the processing plant and are optimised individually, while their economic and environmental impacts are briefly assessed.

Besides focusing on the ways to design compact and low-weight steam cycles, it is critical to analyse the site-scale integration of such technologies. The various system configurations and the synergies between the gas turbines, the steam network, the cooling system and the processing plant should be identified and investigated systematically to improve the performance of the overall plant. The literature lacks the application of systematic energy and process integration approaches to such systems, and the objectives of the present work are therefore to:

- assess the thermoenvironomic (i.e. energetic, economic and environmental) performance of an existing oil and gas platform;

- evaluate the prospects and challenges associated with the integration of steam cycles at a site-scale level, by systematic process integration, rather than at the level of the combined cycle solely;

- estimate the total costs, local and life cycle $\mathrm{CO}_{2}$-emissions and fuel savings simultaneously, as well as other environmental impacts, by considering the multi-period and multi-objective aspects of this optimisation problem.

\section{Methodology}

\subsection{System description}

\subsubsection{General overview}

Oil and gas from the field reservoir, mixed with subsurface water, enter the production facility through several wells and via several pipelines. They are always extracted at high pressures (10-200 bar) but with temperatures either below $\left(\leq 10^{\circ} \mathrm{C}\right)$ or above $\left(\geq 60{ }^{\circ} \mathrm{C}\right)$ the ambient ones, depending on the oilfield. The aim of an oil and gas facility is to separate the oil, gas and water phases on-site (Figure 1): oil is sent to the shore for further treatment in refineries, gas is either exported or injected back to the reservoir to enhance oil production, and water is chemically treated and rejected to the sea. In some cases, the produced water is injected into the reservoir to maintain a high pressure [1].

Separation of the oil, water and gas phases is conducted in several stages, operated at different pressures and temperatures. The pressures are decreased by throttling valves, near the atmospheric pressure $(\simeq 1.5-$ 2.5 bar), and the temperatures can be increased at each stage to ease the recovery of light hydrocarbons. Oil is then cooled down and pumped to the pressure required for export.

The recovered gas is compressed to the initial feed pressure and may be compressed further if it is injected or exported ( $\simeq 100-250$ bar). It may be dehydrated by physical absorption with glycol, in order to prevent corrosion issues in pipelines. A fraction of the treated gas is sent to a fuel gas system, where it is heated before combustion in gas turbines for on-site power generation. The light- and medium-weight hydrocarbons removed from the gas treatment can either be mixed with oil or gas, or treated in a distillation sequence to avoid that butanes and pentanes are exported along with gas.

Produced water is treated in a dedicated section, in which solid particulates and dissolved hydrocarbons are removed by physical and chemical treatment. The cleaned produced water is either discharged into the sea or injected to the reservoir $(\simeq 120-200$ bar $)$ to enhance oil recovery. 


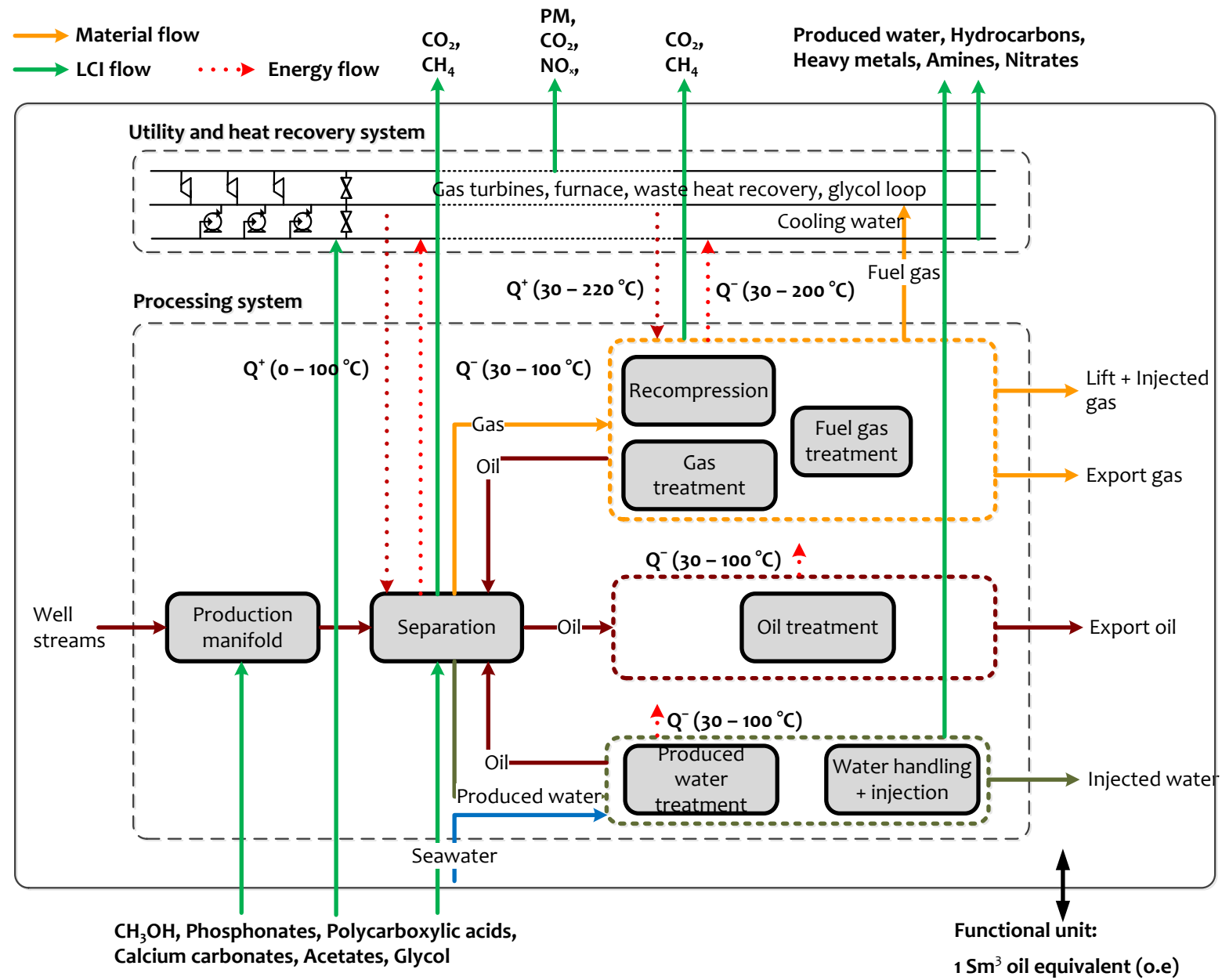

Figure 1: A generalised overview of the oil and gas processing on an offshore platform.

Gas flaring and venting is subject to stricter regulations on several oil producing regions, including the North and Norwegian Seas [6,9]. They have been practised in case of unexpected situations (e.g. sudden production rise) but these emissions are less and less frequent.

\subsubsection{Case study}

The present work deals with the analysis of an existing platform [20], and the benefits of process integration and of optimising the operating conditions of steam cycles are discussed. This Norwegian Sea platform has been in production for about 20 years (Figure 2). The oil and gas peak productions were reached several years ago, and the facility currently exports about $230 \mathrm{t} / \mathrm{h}$ of oil and $30 \mathrm{t} / \mathrm{h}$ of gas. About $1100 \mathrm{t} / \mathrm{h}$ of produced water is discharged to the sea. Seawater is lifted to meet the cooling requirements on-site [21].

Fuel gas is burnt in two gas turbines run at slightly less than $50 \%$ load to meet the power requirements, while a third one is on standby (SGT-500) $[22,23]$. Additional fuel gas is consumed in two other gas turbines, which are exclusively dedicated to the water injection pumps. The heating demand of the processing plant itself amounts to $4 \mathrm{MW}$, but it used to be higher when the oil production was larger, and it is ensured by waste heat recovery from the turbine exhausts and electric heating. The exhaust gases, at a temperature generally higher than $330{ }^{\circ} \mathrm{C}$, deliver heat to an intermediate glycol loop, which transfers heat to the oil and condensate streams in the processing plant. Heating is required in the separation sub-system, as well as in 


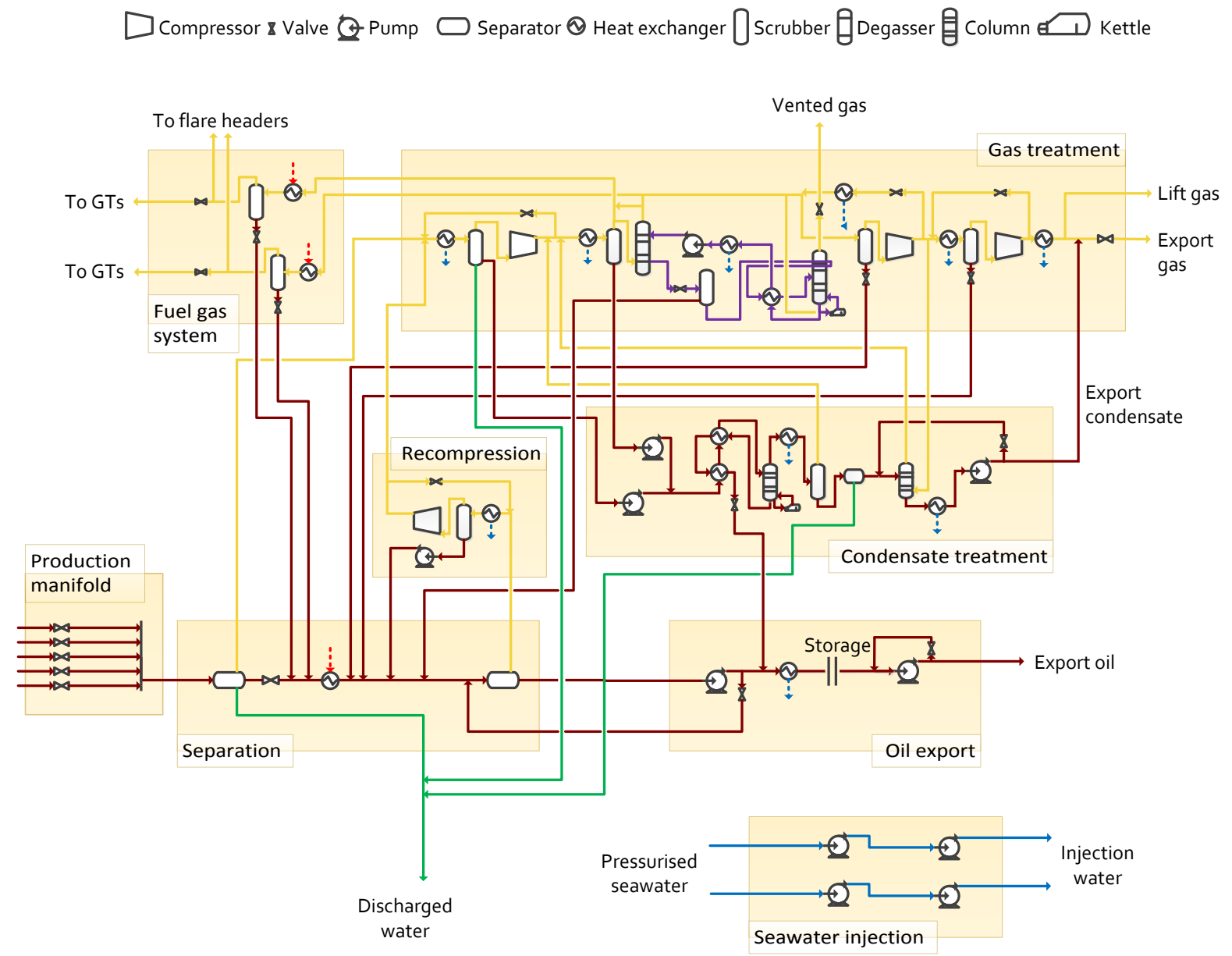

Figure 2: Process flow diagram of the Norwegian facility considered in this work.

two distillation columns to fractionate oil and regenerate the glycol used for dehydrating gas [24].

Two main operating modes can be identified: (i) the processed oil is stored in tanks installed at the bottom of the facility and the total power demand ranges around 18-19 MW, and (ii) oil is loaded into shuttle tankers, which results in a total power consumption of about 24-25 MW. This implies that the gas turbines are run at different loads, which differ from their nominal operating conditions. The power demand may also vary, depending on whether the seawater injection system, which aims at producing high-pressure water for improving the oil recovery, is used. These variations in power demand as well as these operating modes are specific to this platform, as other facilities may use other oil recovery techniques.

The present study aims at analysing the possibilities for implementing a steam cycle on this specific facility, and at giving hints on which aspects should be considered when investigating the integration of such cycles on oil and gas platforms. The installation of a steam cycle would result in a smaller fuel consumption per unit of power produced and in a greater power reserve, which would be useful in the case that the required power demand increases. This case may be faced if, for instance, the need for seawater injection rises as the oil production decreases, or if other processes are implemented at a later point of time.

\subsubsection{Integration possibilities}

Different scenarios can be drawn when integrating a steam cycle, depending (i) on the selection of the cold utility, (ii) on the recovery of waste heat from one or two gas turbines, and (iii) on the use, or not, of 
an intermediary heating loop (tri-ethylene glycol). Three potential heat sinks can be identified: (i) seawater at about $8^{\circ} \mathrm{C}$, which needs to be lifted and pumped to the pressure of the water distribution network, (ii) cooling water from the process, which is treated seawater already available on-site at about $16.5^{\circ} \mathrm{C}$, and (iii) produced water from the oil extraction, which contains oil traces and pollutants, and is at a temperature of about $60-70{ }^{\circ} \mathrm{C}$. These possible scenarios can be summarised in a superstructure of the gas turbine - steam network - cooling utility systems, in which all the possible technologies are embedded (Figure 3).

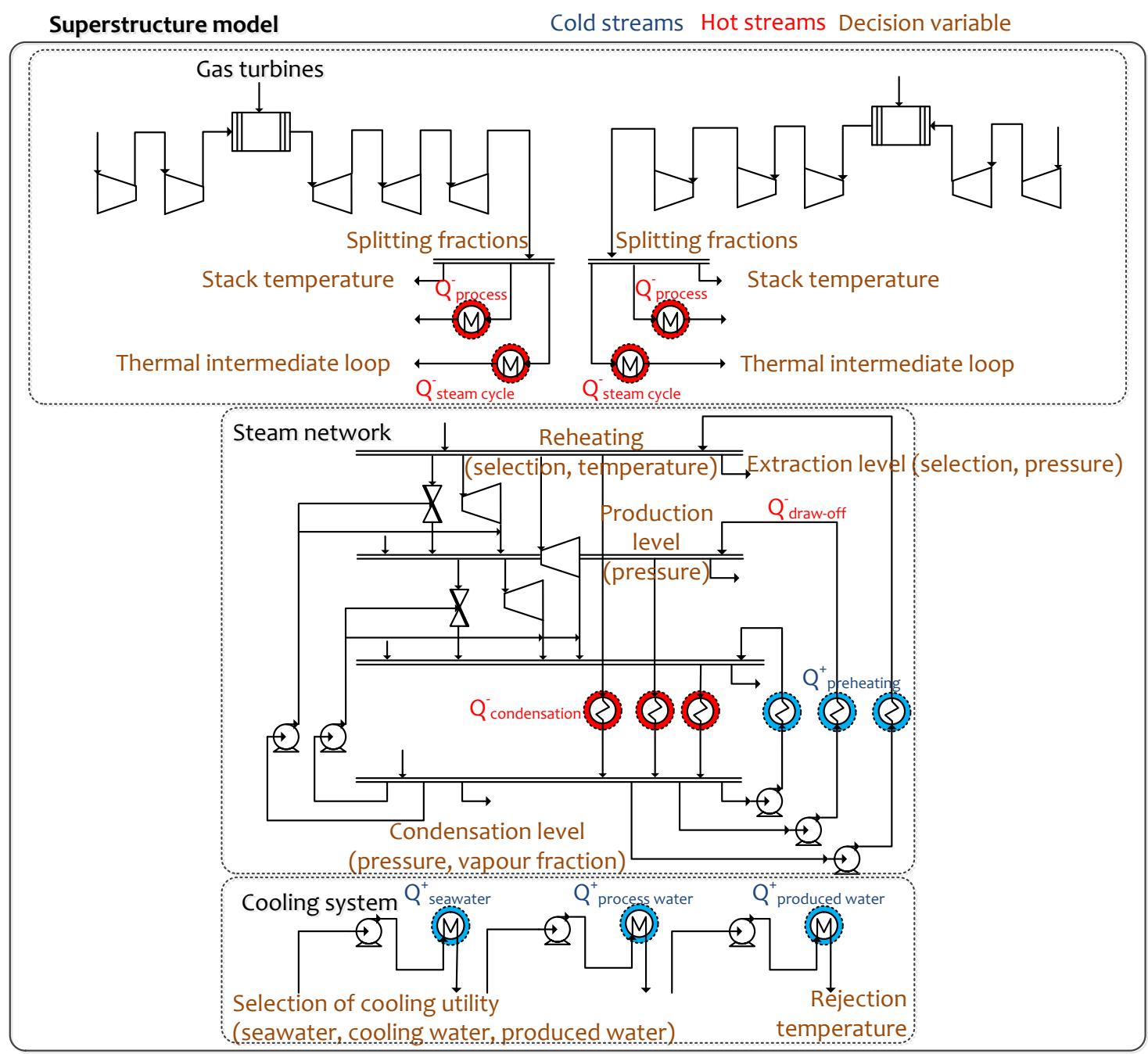

Figure 3: Superstructure of the steam cycle integration with the gas turbines and cooling systems, adapted from [25].

\subsection{Thermoenvironomic modelling}

This work follows a design and optimisation methodology that has been applied for the conception of, among others, hydrogen processes [26] and biomass conversion processes [27]. The aim is to define the system configurations that, for example, simultaneously minimise the economic costs or environmental impacts, while maximising the internal heat recovery and the thermodynamic performance [25]. The problem includes discrete and continuous variables, as well as linear and non-linear relationships among them. It is 
therefore a MINLP (Mixed Integer Non-Linear Programming) problem, decomposed in this work into two sub-problems, namely a master and a slave optimisation problem (Figure 4).

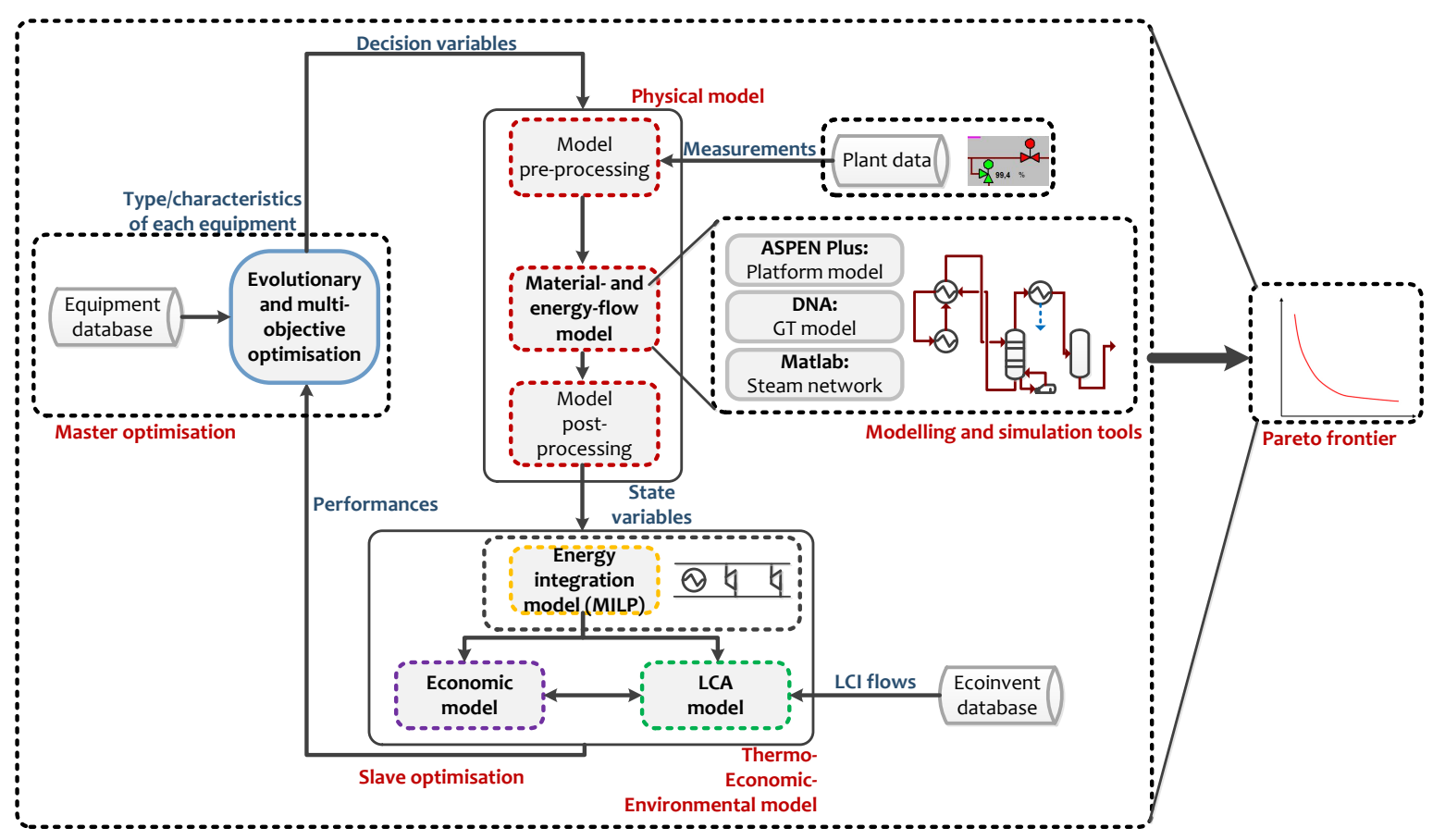

Figure 4: Illustration of the applied methodology and computational framework, adapted from [26,28]

The first step consists of developing a physical model of the system of interest: it builds on a superstructure including all the different technological options and uses process simulation software to calculate the energy and material flows, for a predefined set of operating conditions. The process simulations were carried out with Aspen Plus ${ }^{\circledR}$ version 7.2 [29], based on (i) the Peng-Robinson (PR) equation of state (EOS) [30] and (ii) the Schwartzentruber-Renon EOS [31,32]. Petroleum is modelled as a group of known and hypothetical (also called pseudo-components), and their properties are derived from the true boiling curve. The gas turbines were simulated with the in-house tool Dynamic Network Analysis (DNA) [33]. The simulation of the overall facility is based on measured and reconciliated data provided by the plant operators.

Since the facility is operated in different operating modes, the part-load behaviour of the gas turbines and steam cycle should be entered as input data in the process design framework, in order to predict the possible fuel savings and reductions in $\mathrm{CO}_{2}$-emissions. The compressor off-design characteristics were derived by applying a stage-stacking analysis [34-36], while the calculations of the isentropic efficiency of each stage were based on the pressure drop assumptions presented in Templalexis et al. [37], and the works of Lieblein [38] and Saravanamuttoo et al. [39]. The gas turbine off-design characteristics were derived following the method described in Stodola [40] and in Traupel [41].

The resulting state variables (e.g. temperature and pressure) and flows (e.g. mass, heat and power) are used, in a second step, in an energy- and process integration model. The opportunities for heat recovery and co-generation are assessed and the system interactions are optimised, with regard to a minimum operating costs or, alternatively, to a maximum power production. This slave sub-problem is a MILP (Mixed Integer Linear Programming) problem, subject to the thermodynamic constraints related to the heat cascades, and for which the decision variables are the utilisation factors of each technology defined in the superstructure [42]. The interactions between each sub-system or utility within the overall system are evaluated by 
investigating the integrated composite curves [43].

The data returned by these physical- and energy-integration models are then processed in a postcalculation step, where an economic and environmental evaluation is performed. The costs of the different equipments are estimated based on the capacity-based correlations presented in Turton et al. [44], which have an uncertainty of $\pm 30 \%$, and the assumptions presented in Table 1 . The dry weight of the steam cycle is calculated based on the estimations of Nord and Bolland [16] for offshore steam cycles. A detailed analysis of the weight and space occupied by the steam cycle is out of scope of the present study, as this mainly depends on the weight and type of each individual component and on the piping connections that would be required. For instance, for the same temperature requirements, a shell-and-tube or a plate-and-frame heat exchange would not occupy the same volume, and the selection of one rather than the other is based on the engineers' experience. The limitations regarding weight and space may vary significantly from one platform to another, as different facilities present different structures (e.g. floating production, gravity-based, tension-leg, etc.).

The environmental impacts are calculated by performing a life cycle assessment of the system equipment and operation, following the approach of Gerber et al. [27]. They are normalised with regards to the FU (functional unit) of this system, which is here taken as $1 \mathrm{Sm}^{3}$ of oil equivalent exported to the shore. The LCI (life cycle inventory) flows, e.g. the elementary flows associated with, for instance, the pollutant emissions during operation, are calculated and their impacts are computed from the Ecoinvent ${ }^{\circledR}$ database [45] (Figure 1). Each scenario is compared using two impact assessment (LCIA) categories: the climate change impact, based on the methods proposed by the Intergovernmental Panel on Climate Change (IPCC) and the endpoint eco-indicator 99, which lumps all environmental impacts on a single score.

The overall thermodynamic, economic and environmental performance is then evaluated based on userdefined indicators, and a multi-objective optimisation is performed, using an evolutionary algorithm [46, 47]. The competing objectives and resulting trade-off are identified. The optimal system configurations are compared and illustrated in the form of a Pareto optimal frontier [48], which shows graphically the optimisation solutions where any individual better-off would result in at least one individual worse-off.

Table 1: Assumptions for the evaluation of the process economics.

\begin{tabular}{ll}
\hline Parameter & Value \\
\hline Marshall and Swift index & 1473.3 \\
Expected lifetime [years] & 30 \\
Interest rate [\%] & 10 \\
Yearly operation [h/year] & 8000 \\
$\mathrm{CO}_{2}$-tax (Norway) [NOK/tCO $][21]$ & 410 \\
Conversion factor [NOK/\$] & 0.16 \\
\hline
\end{tabular}

\subsection{Thermoenvironomic optimisation}

\subsubsection{Performance indicators}

Several indicators characterising the performance of the utility plant solely and of the overall plant can be defined to compare the different integration alternatives and scenarios.

Thermodynamic indicators The performance of the overall plant is assessed by the energy intensity of the oil and gas facility, which is an indicator widely used in the oil and gas industry [6,49]. It is defined as the ratio of the energy used on-site to the energy exported to the shore with oil and gas:

$$
\sigma=\frac{\Delta h_{\mathrm{FG}}^{0} \cdot \dot{m}_{\mathrm{FG}}}{\Delta h_{\mathrm{OIL}}^{0} \cdot \dot{m}_{\mathrm{OIL}}^{-}+\Delta h_{\mathrm{GAS}}^{0} \cdot \dot{m}_{\mathrm{GAS}}^{-}}
$$

where $\Delta h^{0}$ stands for the lower heating value and $\dot{m}$ for the corresponding mass flow.

The performance of the combined cycle solely is assessed by calculating the energy efficiency $\eta_{\mathrm{CC}}$, defined as: 


$$
\eta_{\mathrm{CC}}=\frac{\dot{Q}^{-}+\dot{W}^{-}}{\Delta h_{\mathrm{FG}}^{0} \cdot \dot{m}_{\mathrm{FG}}^{+}}
$$

where $\dot{Q}$ and $\dot{W}$ represent the energy transfers with heat and power. The superscripts ${ }^{+}$and ${ }^{-}$illustrate the input and output flows. This definition considers that the heat output is useful, as it is the case for a combined cycle with heat extraction, i.e. for a combined heat and power utility plant.

Economic indicators The economic aspects are assessed by calculating the additional investment costs $C_{\text {inv }}$, associated with the steam cycle integration, and the higher profits, related to the reduction of the $\mathrm{CO}_{2}$-emissions and the savings in fuel gas consumption.

The operating costs are related to (i) the additional cooling water and pumping demands on-site for the steam condensation, (ii) the equipment maintenance costs, (iii) the money savings with the reductions of $\mathrm{CO}_{2}$-taxes, (iv) the money earnings with the increases of gas sales.

The fuel gas has a lower quality than the exported gas, as it has not been dehydrated and purified in the last compression stages. The increase of the amount of gas exported to the shore is not equal to the reduction in the amount of fuel gas. The marginal increase of export gas is estimated, based on the operating data and simulations, to $0.98 \mathrm{~kg}$ per $\mathrm{kg}$ of fuel gas.

The economic value of the exported gas streams cannot be estimated accurately. This gas is sent through the Åsgard pipeline system: it is mixed with natural gas from the other petroleum fields located in the northern part of the North Sea, and these flows have different chemical compositions (e.g. lightand medium-weight hydrocarbon contents) and physical properties (e.g. viscosity and heating value). The mixed streams are then treated at the Kårst $\varnothing$ plant, in which they are split and refined into a large variety of hydrocarbons (natural gas and liquid petroleum gases) that are exported worldwide. Calculating the economic value of a single natural gas stream is therefore difficult, as this would require (i) the measurements of the exact flow rates and compositions of the gas streams from the other facilities, and (ii) a forecast of the variations of the natural gas prices on the market, for different countries. On the contrary, the relative increase of the export gas flow is a clearer and less controversial performance indicator, which depends solely on the facility under study.

Finally, it is assumed that the integration of a steam cycle into an existing offshore plant does neither result in an increase of the number of operators, nor in a higher operator's salary. The additional operating costs can therefore be neglected, and the economic performance of the steam cycle integration can be assessed with regards to the potential fuel gas savings and reductions in $\mathrm{CO}_{2}$-taxes. The profitability of the steam cycle integration is thus assessed by the relative increase in exported gas $\delta_{\mathrm{NG}}$, which is expressed as:

$$
\delta_{\mathrm{NG}}=\frac{\dot{m}_{\mathrm{NG}}-\dot{m}_{\mathrm{NG}, \mathrm{REF}}}{\dot{m}_{\mathrm{NG}, \mathrm{REF}}}
$$

Performance indicators such as the net present value or the payback time, which combine in a single metric the capital and operating costs, are not considered in this study. They would require a precise knowledge of the economic benefits made by the platform operators for exporting additional gas, which are difficult to estimate for the reasons mentioned above.

Environmental indicators The environmental aspects are investigated by calculating several factors related to the emissions of pollutants during the operation (local emissions) and during the life cycle (building, installing and decommissioning the components on-site). The reduction of the local $\mathrm{CO}_{2}$-emissions $\left(\delta_{I_{\mathrm{CO}_{2}}}\right)$ as well as of the global warming potential over the life cycle of the oil and gas facility $\left(\delta_{I_{\mathrm{GWP} 100}}\right)$ can be expressed as:

$$
\begin{aligned}
\delta_{I_{\mathrm{CO}_{2}}} & =\frac{I_{\mathrm{CO}_{2}}-I_{\mathrm{CO}_{2}, \mathrm{REF}}}{I_{\mathrm{CO}_{2}, \mathrm{REF}}} \\
\delta_{I_{\mathrm{GWP} 100}} & =\frac{I_{\mathrm{CO}_{2}-\mathrm{EQ}, \mathrm{REF}}-I_{\mathrm{CO}_{2}-\mathrm{EQ}}}{I_{\mathrm{CO}_{2}-\mathrm{EQ}, \mathrm{REF}}}
\end{aligned}
$$


where $I_{\mathrm{CO}_{2}}$ and $I_{\mathrm{CO}_{2}}$, REF denote the local $\mathrm{CO}_{2}$-emissions of the reference and investigated scenarios, respectively, per unit of oil and gas exported to the shore. Similarly, $I_{\mathrm{CO}_{2}-\mathrm{EQ}, \mathrm{REF}}$ and $I_{\mathrm{CO}_{2}-E Q}$ denote the equivalent $\mathrm{CO}_{2}$-emissions, over a life horizon of 100 years. The use of carbon dioxide equivalence allows for accounting on the same basis, and over a specific time-scale, the effect of the several greenhouse gases emitted during the production, building and decommissioning of the oil facility.

A reduction of the $\mathrm{CO}_{2}$-emissions presents also economic benefits, as it results in lower taxes paid by the oil companies. In the following, unless specified the opposite, the term $\mathrm{CO}_{2}$-emissions refers to the local emissions, and not to the emissions of $\mathrm{CO}_{2}$ during the life cycle.

The other environmental impacts assessed in this study, on a life cycle basis, are the acidification potential, the eutrophication impact and the marine water ecotoxicity, which are denoted $I_{\mathrm{ACD}}, I_{\mathrm{EUT}}$ and $I_{\text {MAETP, }}$ respectively.

\subsubsection{Multi-objective optimisation}

The trade-off between several competing factors is evaluated by performing a multi-objective optimisation (MOO), based on an evolutionary algorithm. The steam cycle operating parameters and strategy, the selection of the cold and hot utilities, and the implementation of a heating loop are defined as master decision variables to ensure that all possible configurations are explored during the optimisation phase (Table 2). The ranges of values for the decision variables related to the steam network (e.g. production level, degree of superheating, reheating, extraction and condensing levels) are based on a preliminary study of the steam cycles already installed offshore and of the current combined cycles that are typically used in power plants. The maximum values for the rejection of the seawater, cooling and produced waters are based on the limitations and recommendations presented in the manufacturing data of the separators and heat exchangers for several oil and gas facilities. The minimum gas exhaust temperature is set to avoid possible corrosion issues in the pipes because of the presence of sulphur compounds and other impurities.

Table 2: Set of the master decision variables used in the multi-objective optimisation of the steam cycle.

\begin{tabular}{|c|c|c|c|}
\hline Variable & Type & Unit & Range/Value \\
\hline Production level & continuous & bar & {$[5-50]$} \\
\hline Degree of superheating & continuous & $\mathrm{K}$ & {$[0-50]$} \\
\hline Selection of reheating & integer & - & $\{0 ; 1\}$ \\
\hline Reheating level & continuous & $\mathrm{K}$ & {$[300-523]$} \\
\hline Selection of 2 nd production level & integer & - & $\{0 ; 1\}$ \\
\hline 2nd production level & continuous & bar & {$[1-50]$} \\
\hline Selection of extraction level & integer & - & $\{0 ; 1\}$ \\
\hline Extraction level & continuous & $\mathrm{K}$ & {$[300-523]$} \\
\hline Condensation level & continuous & $\mathrm{K}$ & [298-343] \\
\hline Vapour fraction (turbine outlet) & continuous & - & {$[0.8-1]$} \\
\hline Selection of seawater & integer & - & $\{0 ; 1\}$ \\
\hline Selection of processed cooling water & integer & - & $\{0 ; 1\}$ \\
\hline Selection of produced water & integer & - & $\{0 ; 1\}$ \\
\hline Selection of thermal intermediate loop & integer & - & $\{0 ; 1\}$ \\
\hline \multirow[t]{3}{*}{ Rejection temperature } & continuous & $\mathrm{K}$ & [281-318] (seawater) \\
\hline & continuous & $\mathrm{K}$ & [288-318] (processed cooling water) \\
\hline & continuous & $\mathrm{K}$ & [338-368] (produced water) \\
\hline Use of exhaust gases from the 2 nd GT & integer & - & $\{0 ; 1\}$ \\
\hline Exhaust temperature (after SC) & continuous & K & {$[393-453]$} \\
\hline Gas turbine load for the SC design point & continuous & $\%$ & {$[40-100]$} \\
\hline Power share between the CC and the 2nd GT & continuous & $\%$ & [50-90] \\
\hline
\end{tabular}

The large variety of performance indicators that can be considered as objectives illustrates that optimal decisions need to be taken with regards to trade-off between two or more competing objectives. An example is the trade-off between the thermodynamic efficiency of the utility plant, which is improved with the 
integration of a steam cycle, and the investment costs, which rise because of the greater equipment inventory and the additional resources consumed for manufacturing and decommissioning the components and substructure. The following three objectives are considered:

1. the net power generation of the utility system, which includes the combined cycle and the associated pumping utilities, to be maximised, so that the combined cycle has the capacity to cover the power demand in the different operation modes of the plant;

2. the investment costs $C_{\mathrm{INV}}$ of the additional bottoming cycle, to be minimised;

3. the daily local $\mathrm{CO}_{2}$-emissions, to be minimised. The economic value of the exported gas is difficult to estimate, but maximising the annual profit is equivalent to maximising $\delta_{\mathrm{NG}}$ and $\delta_{I_{\mathrm{CO}_{2}}}$ simultaneously.

The degrees of association between the decision variables and the objectives can be statistically characterised by the Pearson's linear correlation coefficients $\rho$. They measure the influence of a decision variable on an objective: 1 denotes a positive correlation, 0 the absence of a correlation, and -1 a negative correlation. The Pearson's partial linear correlation coefficients, denoted $\rho_{\text {PART }}$ measure the influence of a given decision variable on each objective, when the effects of all other decision variables are removed, i.e. when all other decision variables are fixed [50,51].

The dispersion of the optimal values of the decision variables, in relation to a particular objective, can be assessed by plotting an histogram of the number of observations in the Pareto set. The bar lengths are proportional to the number of points on the Pareto frontier for a subinterval of the decision variable, and the colour shadings are related to the ranking of a given Pareto point, with respect to the objective of interest.

\section{Results and discussion}

\subsection{Current situation}

The current system configuration, with the corresponding fuel gas consumption and environmental impact, is taken as reference scenario to which the other configurations are compared. Both the electrical and heating demands are met by running the gas turbines on-site, and by recovering the waste heat from the exhaust gases on three of them.
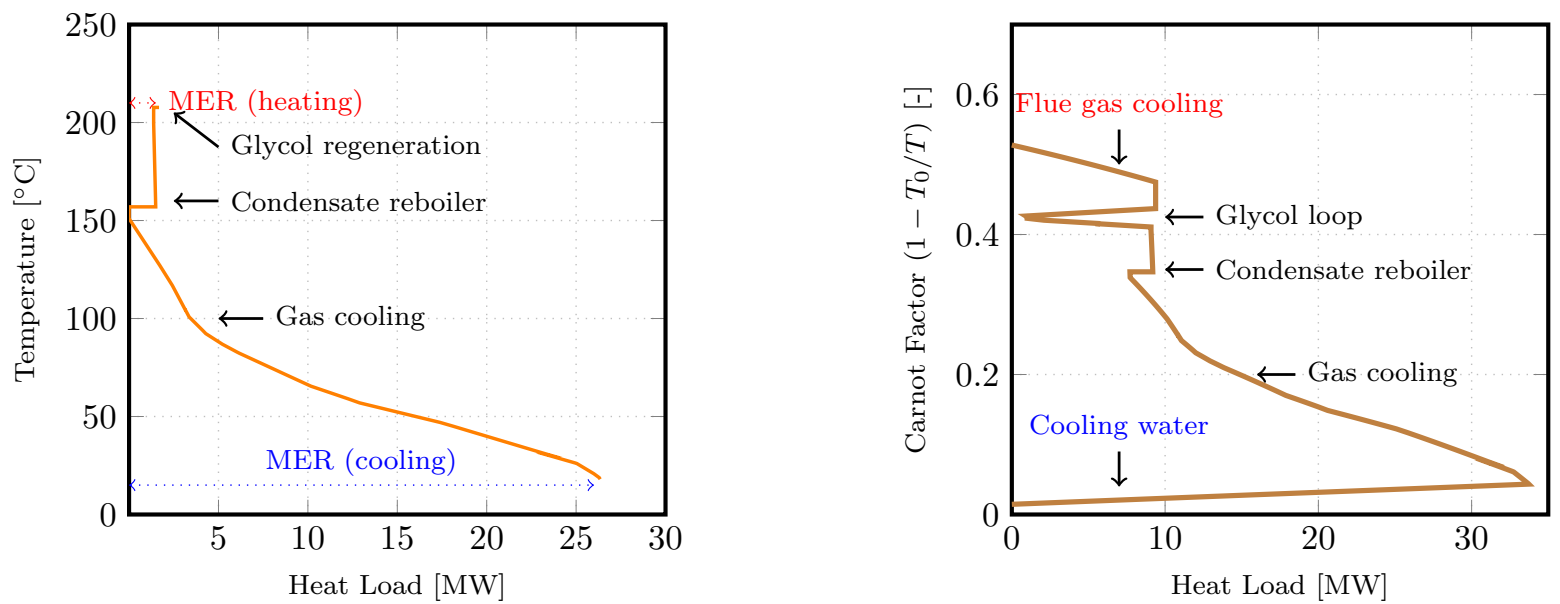

Figure 5: Composite curves of the oil and gas facility: Grand Composite Curve of the oil and gas processing (left) and Balanced Grand Composite Curve of the offshore plant (right).

The GCC (Grand Composite Curve) of the process streams (Figure 5) illustrates that the MER (minimum energy requirement) for external heating is smaller than 2 MW. The MER for external cooling amounts to more than $25 \mathrm{MW}$, below $30{ }^{\circ} \mathrm{C}$. The $\mathrm{GCC}$ of the process streams together with the utilities, i.e. the BGCC (Balanced Grand Composite Curve) reveals the significant exergy destruction taking place in the 
heat exchanges between the gas turbine exhausts, the process streams, and the intermediate glycol loop used in-between. The exergy destruction and losses associated to the heat exchange system are related to the area between the BGCC and the temperature-Carnot axis.

This available exergy located below the utility pinch at about $320{ }^{\circ} \mathrm{C}$ can be partly converted into mechanical power by integrating a steam cycle. Moreover, a greater fraction of the temperature-based (thermal) exergy from the exhaust gases can be recovered by allowing for a lower rejection temperature.

The external heating requirements of the process streams are smaller than $2 \mathrm{MW}$. However, the amount of heat recovered from the exhaust gases by the glycol loop is higher, as hot glycol is stored in a buffer tank to prevent unexpected events and possibly for other heating purposes. This particularity of the heating system is illustrated by the near-utility pinch at about $200-210{ }^{\circ} \mathrm{C}$.

The environmental assessment of the whole platform indicates that the total $\mathrm{CO}_{2}$-emissions amount to about 450 tonnes per day, of which more than $90 \%$ are associated with the natural gas consumption of the gas turbines currently operated. Emissions caused by flaring and venting are negligible in terms of global warming potential.

\subsection{Site-scale integration}

\subsubsection{Thermoenvironomic optimal configurations}

The possible configurations of the steam network are analysed with respect to energetic, economic and environmental criteria. All the solutions displayed on the Pareto-optimal frontier (Figure 6) are based on the use of the cooling water recovered from the processing plant at about $16.5^{\circ} \mathrm{C}$, and on, in a few cases, the lift of additional seawater on-site.

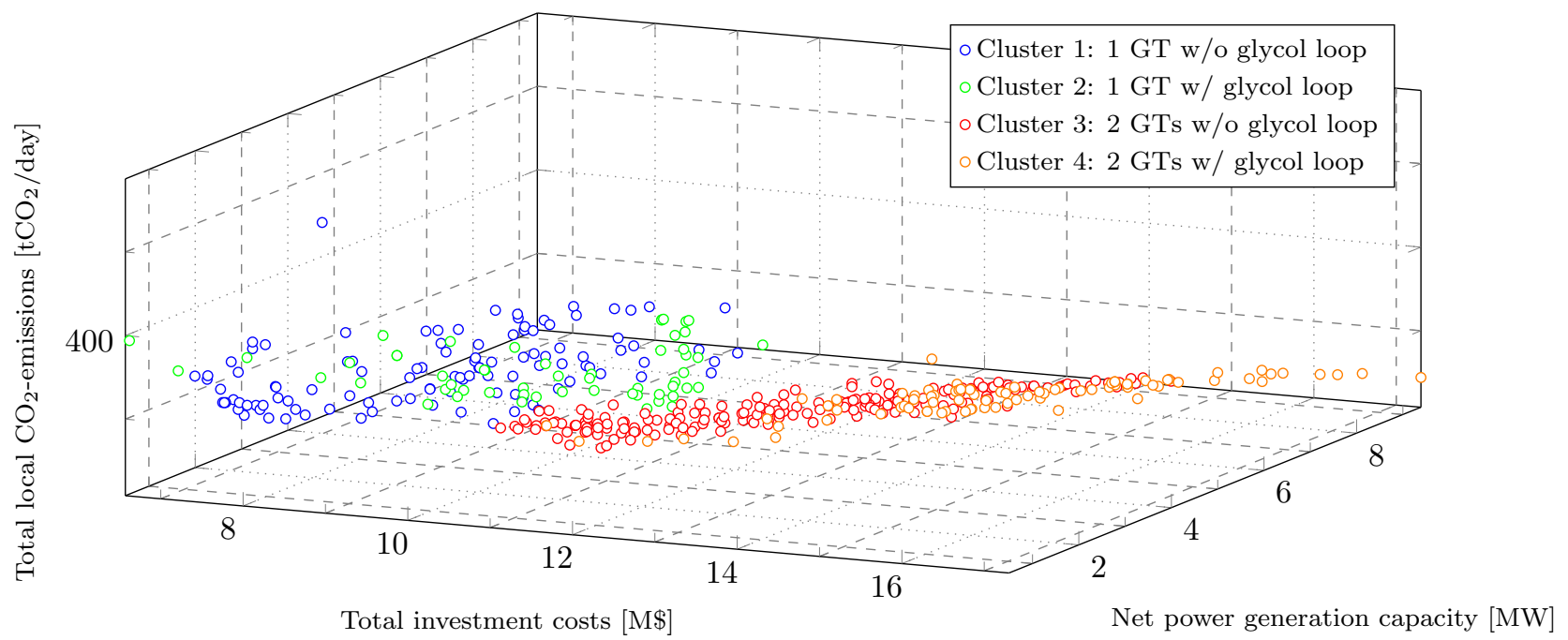

Figure 6: Pareto-optimal solutions for the site-scale integration of steam cycles on offshore platforms: trade-off between the investment costs, $\mathrm{CO}_{2}$-emissions and net power capacity. For readability, the 4 configurations chosen for further study are represented in Figure B.17. The reference point corresponds to a total investment cost of $0 \mathrm{M} \$, 0 \mathrm{MW}$ and 450 tonnes per day.

The design set-ups, in which only seawater at $8^{\circ} \mathrm{C}$ is used, are discarded. This illustrates that the benefits of using a cold source at such a low temperature are outweighed by the additional power consumption to bring this water on-site, and the supplementary costs for installing water lift pumps. Similarly, the configurations, where only the produced water from the oil and gas plant is processed, are not taken into account. The inlet temperature $\left(\simeq 60-70{ }^{\circ} \mathrm{C}\right)$ of this potential utility results in severe limitations on the condensation temperature and on the power generation capacity of the steam cycle, and such solutions are thus sub-optimum.

None of all the optimal design set-ups shown on the Pareto frontier include reheating or an additional production level. This indicates that the relatively low temperature of the heat source (exhaust gases at 
about $330{ }^{\circ} \mathrm{C}$ ) does not favour the use of more than one production (evaporation and superheating) and utilisation (condensation) level. Finally, solutions with an intermediate extraction level are not considered, as the thermodynamic benefits of such solutions are negligible in comparison to the economic penalties induced by a higher system complexity.

The following conclusions can be drawn from the dispersion of the optimal solutions on the thermoenvironomic Pareto frontier. Firstly, the daily $\mathrm{CO}_{2}$-emissions and net power generation capacity respectively decrease and increase with higher investment costs, when the waste heat from the exhaust gases of only one gas turbine is recovered. Secondly, when the waste heat from the exhaust gases of two gas turbines is used, the total $\mathrm{CO}_{2}$-emissions cannot be decreased further down than 360 tonnes per day, and an increase of the investment costs only results in an increase of the net power generation capacity. This trend illustrates that the steam cycle is not run at its design point or maximum capacity. The increase of the power capacity of the steam cycle is performed at the expense of a lower thermodynamic efficiency of the combined cycle at their actual operating point.

Despite the numerous possible configurations embedded in the steam network superstructure, the optimal solutions are distributed in four different clusters, and an example of configuration for each cluster is further studied (Table 3). These four clusters differ by the activation or deactivation of the glycol loop, and by the possible use of the waste heat contained in the exhaust gases from the second gas turbine.

The integrated Carnot composite curves of the steam cycle (Figures 7-8 and Figures A.15-A.16) highlight the thermodynamic benefits of this integration. They show how the steam network is actually integrated with the rest of the plant: the area between the two curves illustrates the exergy destruction associated with the heat transfers on-site, or, alternatively, the exergy pockets that could be exploited further.

- Cluster 1: The steam cycle is integrated with the exhaust gases coming from only one of the two gas turbines. The glycol loop is dismantled and process cooling water is used. The total investment costs vary between 7.2 and $11.7 \mathrm{M} \$$, the net power capacity at the design point of the steam cycle between $490 \mathrm{~kW}$ and $4600 \mathrm{~kW}$, the daily $\mathrm{CO}_{2}$-emissions down to 370 tonnes per day. This corresponds to a reduction of the $\mathrm{CO}_{2}$-emissions of up to $15 \%$ at the scale of the utility plant, and up to $14 \%$ at the scale of the overall facility. Moreover, this corresponds to an increase of the natural gas exportations by up to $18 \%$. The rejection temperatures of the cooling water range between 30 and $40{ }^{\circ} \mathrm{C}$ and the exhaust gas temperatures between 150 and $160{ }^{\circ} \mathrm{C}$.
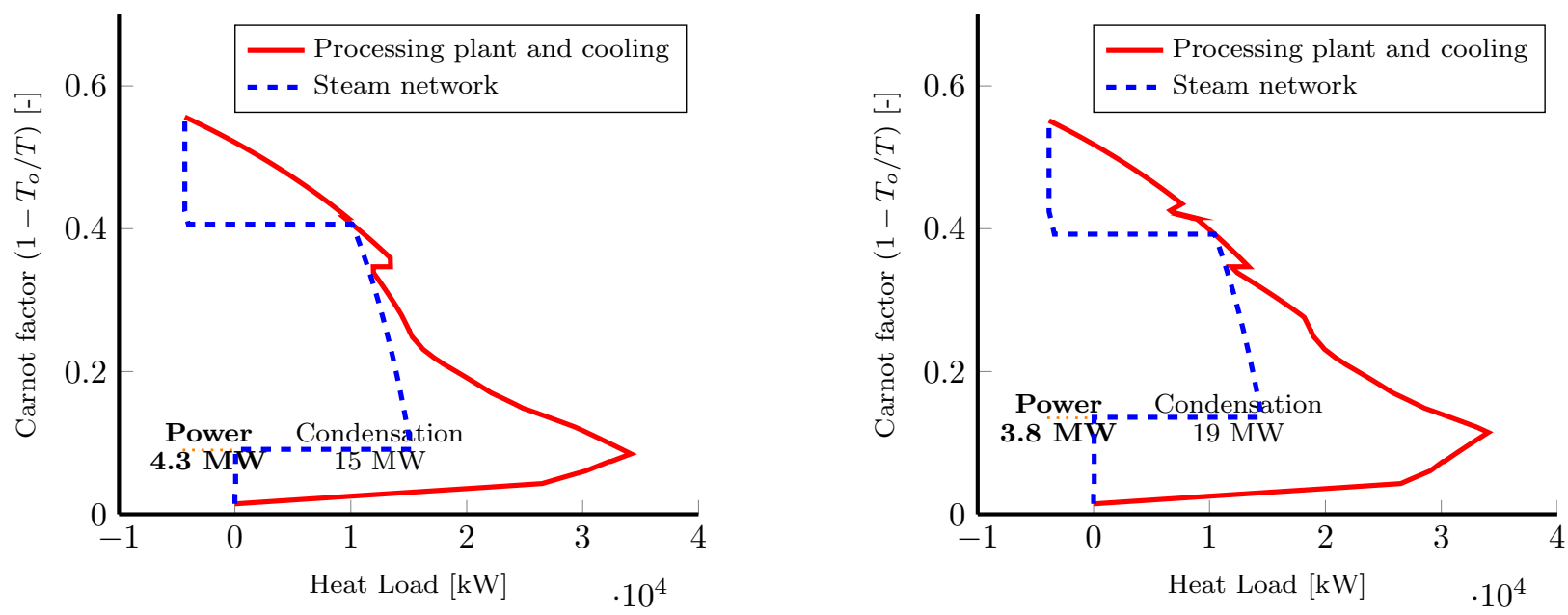

Figure 7: Integrated Carnot Composite Curves (ICC) of the Steam network for an optimum case of Cluster 1 (Configuration A) and Cluster 2 (Configuration B)

The combined cycle setup of the configuration A (Figure 7) reduces clearly the heat losses associated with the rejection of the flue gases from the power turbines, as well as the exergy losses at high temperature. It results in a power production of more than $4 \mathrm{MW}$, but a significant potential for 
exergy recovery can be pointed out at low temperatures $\left(\leq 100{ }^{\circ} \mathrm{C}\right)$. The integration of the steam network actives a new utility pinch point, which is caused by the heating demand of the condensate reboiler at about $150-160{ }^{\circ} \mathrm{C}$.

- Cluster 2: The steam cycle is integrated with the exhaust gases coming from only one of the two gas turbines. A fraction of the exhaust gases is used to satisfy the heating demand of the glycol loop, which is set, in the optimum case, equal to the heating demand of the processing plant. Compared to the reference case, this assumes that there is no additional glycol heating for heat buffering purposes. The reductions in $\mathrm{CO}_{2}$-emissions are similar to the ones retrieved from Cluster 1.

The exhaust gas temperatures are lower by $20 \mathrm{~K}$ in these cases, ranging between 130 and $140{ }^{\circ} \mathrm{C}$, which may be problematic if the gas used in the gas turbines is substituted by a dirtier fuel such as heavy oil or diesel. This may happen in the future, as there is a foreseen fuel gas deficiency for this particular platform. Heavy oil and diesel have a higher content of impurities (e.g. sulphur), which may condense and corrode the pipes.

The integration of a steam network for the configuration B (Figure 7) results in a significant reduction of the waste heat and exergy losses. However, the glycol loop, although it does not activate another utility pinch point, hinders steam production at higher pressure levels. Producing steam above the glycol loop, i.e. above $200-210^{\circ} \mathrm{C}$, would result in smaller condensation losses, at the expense of a smaller power generation. Co-generation of power is also clearly limited by the activation of a utility pinch point at the level of the condensate reboiler, i.e at $150{ }^{\circ} \mathrm{C}$. Producing a greater amount of mechanical power, i.e. above $5 \mathrm{MW}$, requires therefore that a greater amount of heat is available between the two utility pinch points at 150 and $350{ }^{\circ} \mathrm{C}$.

- Cluster 3: The steam cycle is integrated with the exhaust gases coming from the two gas turbines, and the exhaust gases are directly used for meeting the requirements of the processing plant. The investment costs are on average greater by about $20 \%$ compared to the previously proposed solutions, but the net power capacity is greatly enhanced, ranging from 2100 to $8260 \mathrm{~kW}$. The daily $\mathrm{CO}_{2^{-}}$ emissions decrease by about 20-30 tonnes per day compared to the two optimal solutions of the two first clusters. The total savings, compared to the baseline case, can reach up to 60-80 tonnes per day. The rejection temperatures of the cooling water and exhaust gases are sensibly similar to the ones in the first cluster of solutions. These improvements can be attributed to the integration of the steam cycle on the exhaust gases rejected from the two gas turbines, rather than from one only.
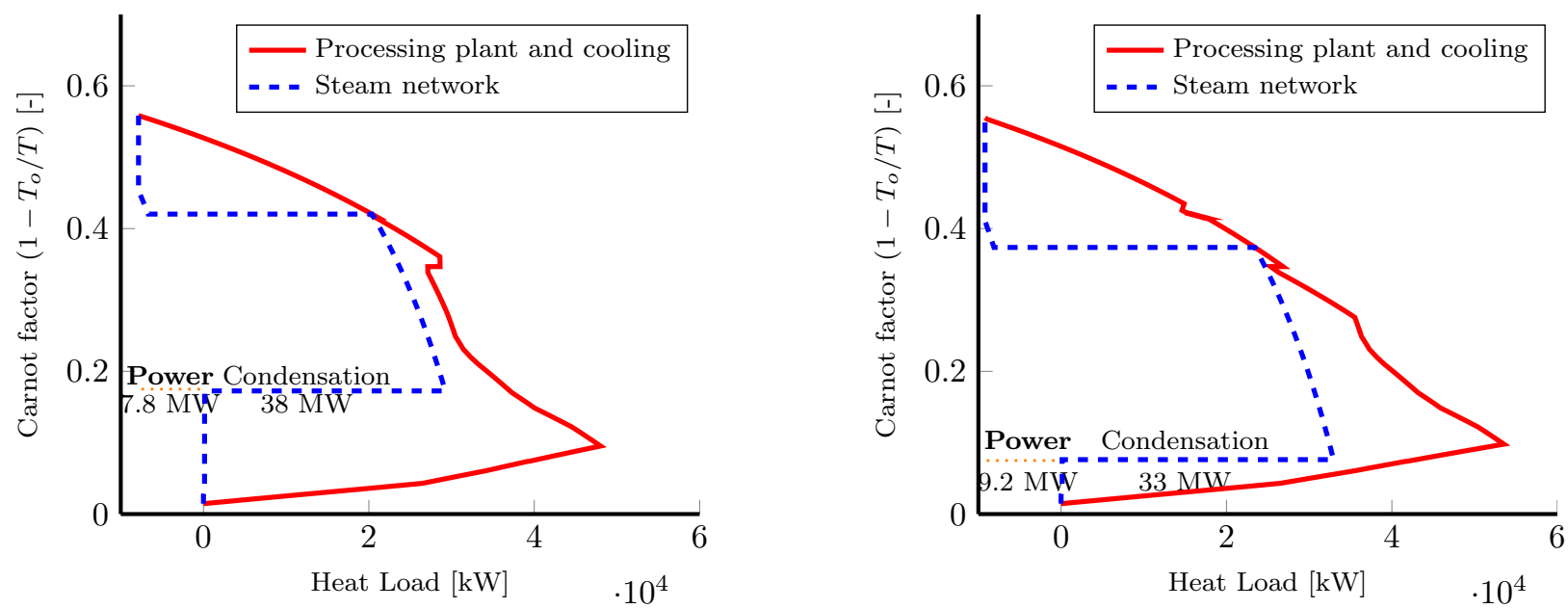

Figure 8: Integrated Carnot Composite Curves (ICC) of the Steam network for an optimum case of Cluster 3 (Configuration C) and Cluster 4 (Configuration D) 
Overall, the use of the two sources of waste heat results in a greater amount of exergy available between 150 and $350{ }^{\circ} \mathrm{C}$ (Figure 8). Steam production takes place at a higher pressure level, in comparison to the previous cases, and the utility pinch point between the condensate reboiler and the steam network is not activated. Steam condensation takes place at a relatively high pressure ( 0.29 bar), and could, in theory, take place at a lower pressure. This case illustrates nevertheless the trade-off between the power capacity of the steam cycle, which would be increased for a lower condensation level, and the economic investment, which would be increased, since the steam turbine would have a higher size.

- Cluster 4: Compared to Cluster 3, the main difference lies in the use of the glycol intermediate loop. The investment costs are higher by $13 \%$ and the net power generation capacity greater by $36 \%$. As expected from the comparison between the solutions displayed in Cluster 1 and in Cluster 2, the stack temperature of the exhaust gases is lower by about $10 \mathrm{~K}$ and the rejection temperature of the cooling water slightly higher.

Both the steam production and condensation take place at lower pressure levels (Figure 8), and the power production is again constrained by the activation of the utility pinch point at $150{ }^{\circ} \mathrm{C}$. This suggests that the exergy losses with the exhaust gases can hardly be reduced further, and that changes in the pressure and temperature levels would result in marginal increases of the power production, at the expense of a smaller part-load efficiency or higher investment costs.

The main drawback is the greater weight and space required for installing and operating the steam cycle, which ranges from 70 to 100 tonnes, as its capacity is much bigger in the configurations obtained in Clusters 3 and 4.

The comparison of the integrated curves for each cluster illustrates the better system integration of the case studied for Cluster 4, compared to the other cases: the exergy destruction due to the heat transfers between the steam cycle and the rest of the plant is smaller. Moreover, they illustrate as well the significant differences that can be found, in terms of system integration, between the optimum cases located on the Pareto frontier.

For instance, the condensation takes place at a high pressure in the case of Configuration $\mathrm{C}(\simeq 0.29$ bar $)$, as no additional seawater is pumped, and the turbine size is reduced to ensure smaller investment costs of the steam network. On the contrary, the condensation takes place at a low pressure in the case of Configuration $\mathrm{D}(\simeq 0.05$ bar $)$, but the capital costs are higher, and the smaller temperature difference in the steam condenser may be problematic.

A comparison of the environmental impacts of each configuration with the current facility shows that the main contributions to the global warming effect of an oil and gas plant are associated with the $\mathrm{CO}_{2}$ emissions with the exhaust gases of the power turbines (Figure 9). Such a conclusion is supported by the annual measurements and data provided by the Norwegian government [21]. The incentives to reduce flaring [9] in this oil region seem to have been effective, since the equivalent $\mathrm{CO}_{2}$-emissions associated with such practices are negligible.

The positive environmental effect of the integration of a steam cycle is also clearly visible when conducting a life cycle assessment. The emissions related to the operation of the steam cycle components, and to the construction and maintenance of them, are greatly compensated by the benefits induced by the reduction in fuel gas consumption and $\mathrm{CO}_{2}$-emissions. The estimation of the eco-points, based on the Ecoindicator 99 method, illustrates the same trends, although the difference between the 4 cases is minor $( \pm 0.01$ ecopoint). The major contribution to the eco-points is associated with the environmental impact of the process components (about 58\%), followed by the impacts of the $\mathrm{NO}_{x}$ (about 23\%) and $\mathrm{CO}_{2}$-emissions (about 15\%). The acidification and eutrophication impacts of the platform are also reduced, as the emissions of nitrogen oxides decrease with a smaller consumption of fuel gas. The platform impact related to the toxicity effects to the marine environment does not vary, as long as there is no change in the petroleum production, and thus no change in the use of and impact of the chemicals.

\subsubsection{Interdependency analysis}


Table 3: Selection of thermoenvironomic optimal configurations: - stands for non-relevant, $\mathrm{y}$ for included, $\mathrm{n}$ for not-included, and ${ }^{*}$ for the gas turbine characteristics, before integration of the steam cycle.

\begin{tabular}{|c|c|c|c|c|c|c|}
\hline $\begin{array}{l}\text { Case } \\
\text { Steam cycle }\end{array}$ & & Reference & $\mathrm{A}$ & $\mathrm{B}$ & $\mathrm{C}$ & $\mathrm{D}$ \\
\hline \multicolumn{7}{|l|}{ Parameters (design point) } \\
\hline Production level & {$[\mathrm{bar}]$} & - & 15.6 & 12.3 & 19.7 & 9.01 \\
\hline Superheating & {$[\Delta \mathrm{K}]$} & - & 15.1 & 25.6 & 28.9 & 28.1 \\
\hline Reheating & & - & $\mathrm{n}$ & $\mathrm{n}$ & $\mathrm{n}$ & $\mathrm{n}$ \\
\hline Extraction & & - & $\mathrm{n}$ & $\mathrm{n}$ & $\mathrm{n}$ & $\mathrm{n}$ \\
\hline Seawater & & - & $\mathrm{n}$ & $\mathrm{n}$ & $\mathrm{n}$ & $\mathrm{n}$ \\
\hline Process water & & - & $\mathrm{y}$ & $\mathrm{y}$ & $\mathrm{y}$ & $\mathrm{y}$ \\
\hline Produced water & & - & $\mathrm{n}$ & $\mathrm{n}$ & $\mathrm{n}$ & $\mathrm{n}$ \\
\hline Glycol loop & & $\mathrm{y}$ & $\mathrm{n}$ & $\mathrm{y}$ & $\mathrm{n}$ & $\mathrm{y}$ \\
\hline Condensation level & {$[\mathrm{bar}]$} & - & 0.07 & 0.15 & 0.29 & 0.05 \\
\hline Vapour fraction (turbine outlet) & {$[-]$} & - & 0.86 & 0.87 & 0.85 & 0.87 \\
\hline Gas turbines & & - & 1 & 1 & 2 & 2 \\
\hline Stack temperature & {$\left[{ }^{\circ} \mathrm{C}\right]$} & 330 & 173 & 123 & 174 & 123 \\
\hline Seawater rejection temperature & {$\left[{ }^{\circ} \mathrm{C}\right]$} & - & - & - & - & \\
\hline Process water rejection temperature & {$\left[{ }^{\circ} \mathrm{C}\right]$} & 16.5 & 29.8 & 40.2 & 33.5 & 34.4 \\
\hline Power share between the $\mathrm{CC}$ and the $2 \mathrm{nd} \mathrm{GT}$ & {$[-]$} & - & 54.5 & 60.7 & 75.0 & 55.6 \\
\hline \multicolumn{7}{|l|}{ Power production [design point] } \\
\hline Steam network generation & {$[\mathrm{kW}]$} & - & 4320 & 3840 & 7840 & 9190 \\
\hline Pumping consumption & {$[\mathrm{kW}]$} & - & 0 & 0 & 0 & 0 \\
\hline Net power generation & {$[\mathrm{kW}]$} & - & 4320 & 3840 & 7840 & 9190 \\
\hline \multicolumn{7}{|l|}{ Thermodynamic performance } \\
\hline Cycle efficiency $\eta_{\mathrm{cc}}$ [design point] & {$[-]$} & $33.7^{*}$ & 34.1 & 32.6 & 38.5 & 39.9 \\
\hline Cycle efficiency $\eta_{\mathrm{cc}}$ [operating point] & {$[-]$} & $23.3^{*}$ & 31.2 & 32.4 & 30.4 & 30.4 \\
\hline Energy intensity $\sigma$ & {$[\%]$} & 4.6 & 4.1 & 4.0 & 3.4 & 3.4 \\
\hline \multicolumn{7}{|l|}{ Economic evaluation } \\
\hline Investment costs & {$[\mathrm{M} \$]$} & - & 11.6 & 11.1 & 15.1 & 16.6 \\
\hline Increase in exported gas $\delta_{\mathrm{NG}}$ & {$[\%]$} & 0 & 9.5 & 10 & 20.3 & 20.2 \\
\hline \multicolumn{7}{|l|}{ Environmental impact } \\
\hline Daily local $\mathrm{CO}_{2}$ emissions & [tonnes/day] & 450 & 398 & 396 & 362 & 362 \\
\hline Decrease of the local $\mathrm{CO}_{2}$-emissions $\delta_{\mathrm{I}_{\mathrm{CO}_{2}}}$ & {$[\%]$} & 0 & 8.7 & 9.2 & 16.9 & 16.8 \\
\hline Global warming potential $I_{\mathrm{GWP} 100, \mathrm{FU}}$ & {$\left[\mathrm{kgCO}_{2}-\mathrm{EQ} / \mathrm{FU}\right]$} & 40.8 & 38.0 & 37.8 & 35.6 & 35.5 \\
\hline Acidification $I_{\mathrm{ACD}, \mathrm{FU}}$ & {$\left[\mathrm{kgSO}_{2}-\mathrm{EQ} / \mathrm{FU}\right]$} & 0.15 & 0.14 & 0.14 & 0.13 & 0.13 \\
\hline Eutrophication $I_{\mathrm{EUT}, \mathrm{FU}}$ & {$\left[\mathrm{kg}_{\mathrm{NO}_{\mathrm{x}}-\mathrm{EQ}} / \mathrm{FU}\right]$} & 0.30 & 0.28 & 0.27 & 0.25 & 0.25 \\
\hline Marine ecotoxicity $I_{\mathrm{MAETP}, \mathrm{FU}}$ & {$\left[\mathrm{kg}_{1,4-\mathrm{DCB}-\mathrm{EQ}} / \mathrm{FU}\right]$} & 65.6 & 65.7 & 65.7 & 65.7 & 65.7 \\
\hline Eco-Indicator 99 & [points/FU] & 2.20 & 2.10 & 2.10 & 2.09 & 2.09 \\
\hline \multicolumn{7}{|l|}{ Other characteristics } \\
\hline Dry weight & [tonnes] & - & 43 & 38 & 78 & 92 \\
\hline
\end{tabular}




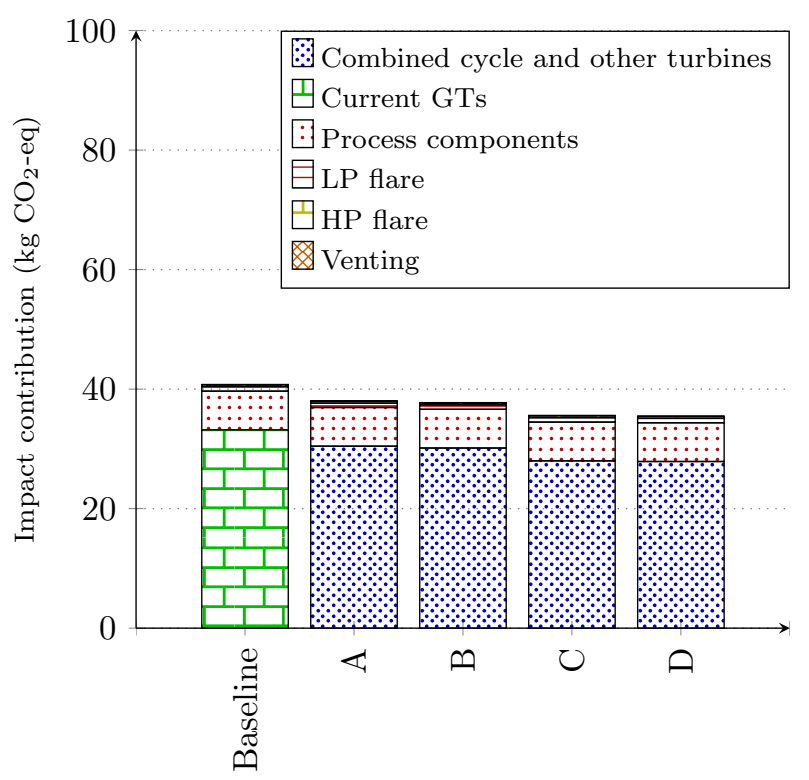

Figure 9: Impact contribution of each process and component on-site, expressed in $\mathrm{kg} \mathrm{CO}_{2}$-eq per functional unit, based on the IPCC-07 method. The global warming potential is shown with an horizon of 100 years.

The main findings of this analysis (Figure 10) can be summarised as follows:

- the condensation level and the allowable vapour fraction at the turbine outlet are the decision variables having the greatest negative influence on the total investment costs, as the cost of the steam turbine increases with the pressure ratio;

- designing the steam cycle for a low steam production level is generally beneficial, because of the greater recovery of the heat from the exhaust gases;

- the selection of the gas turbine loads, at which the steam cycle is designed, is critical: it illustrates a clear conflict between the minimisation of the economic costs and the maximisation of the power capacity;

- the power share between the combined cycle and the 2nd gas turbine has a moderate effect on the investment costs and on the total $\mathrm{CO}_{2}$-emissions: it should be chosen appropriately, considering operational matters (e.g. avoiding surge or choking of the 2nd gas turbine);

- the rejection temperature of the process water impacts mainly the total investment costs, as a smaller temperature difference in the steam condenser results in a larger heat transfer area;

- the influence of the stack temperature is more marked when there is an intermediate heating loop installed on-site, since the glycol medium circulates between 200 and $220{ }^{\circ} \mathrm{C}$, and the waste heat is available at lower temperatures;

- processing seawater in addition to the process cooling water is not particularly beneficial;

- the main difference between the cases where heat is recovered from one stream of exhaust gases, or from two, lies in the importance of the production level and of the degree of superheating;

In the first case (Clusters 1 and 2), there is, apparently, no direct correlation between these two decision variables and the optimal configurations found on the Pareto frontier. On the contrary, in the second case (Clusters 3 and 4), these variables and the optimisation objectives seem interdependent. This can 
Cluster 1

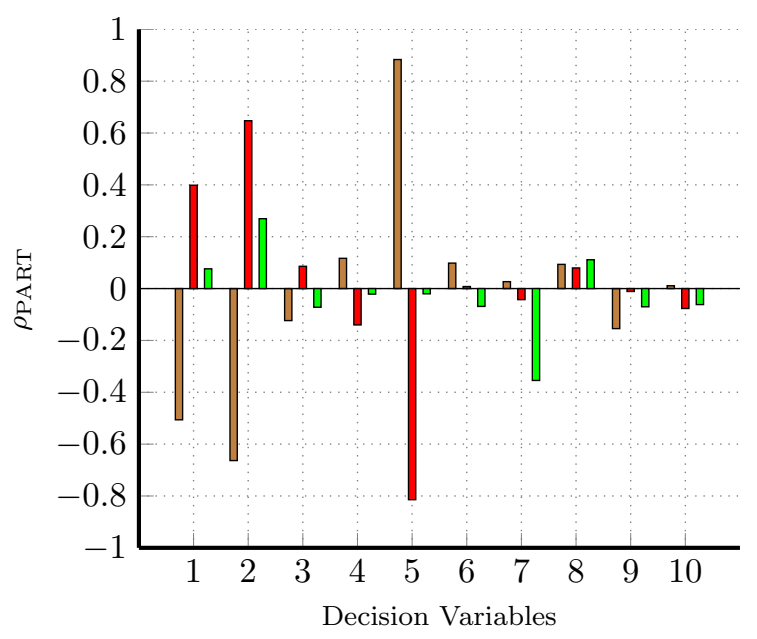

Cluster 3

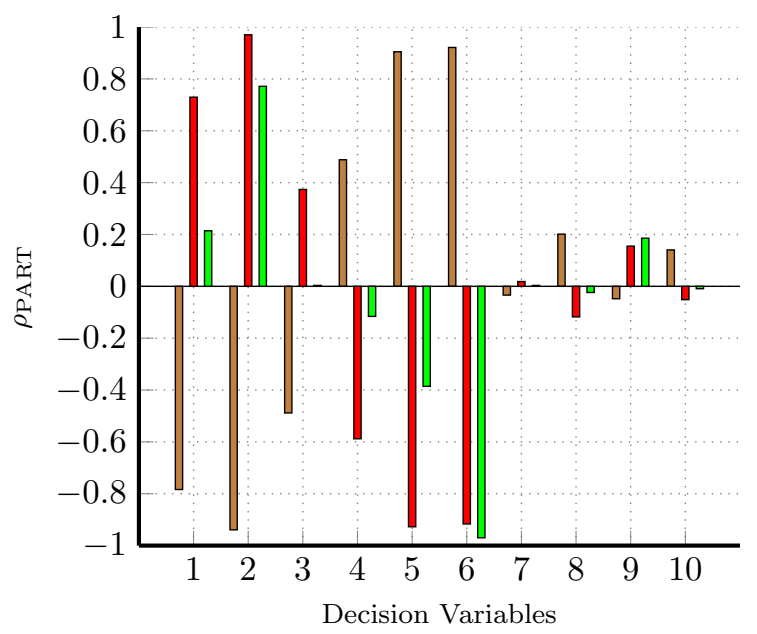

Cluster 2

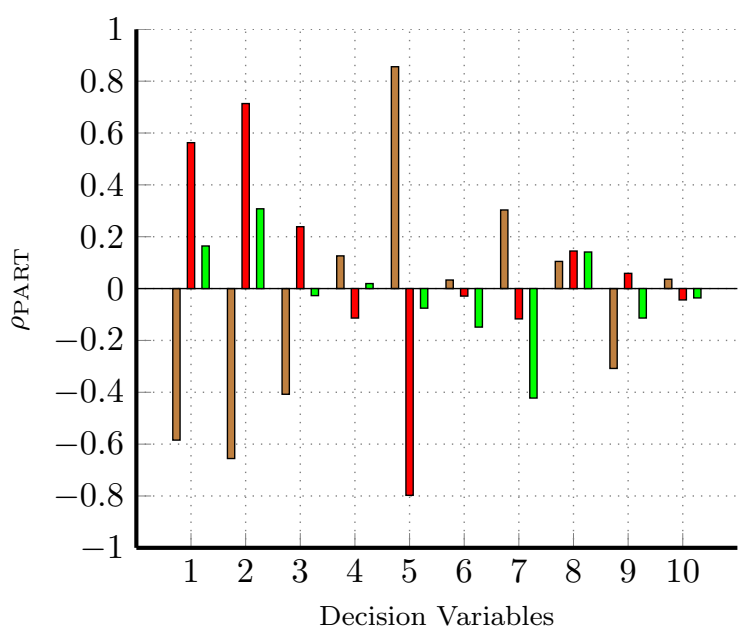

Cluster 4

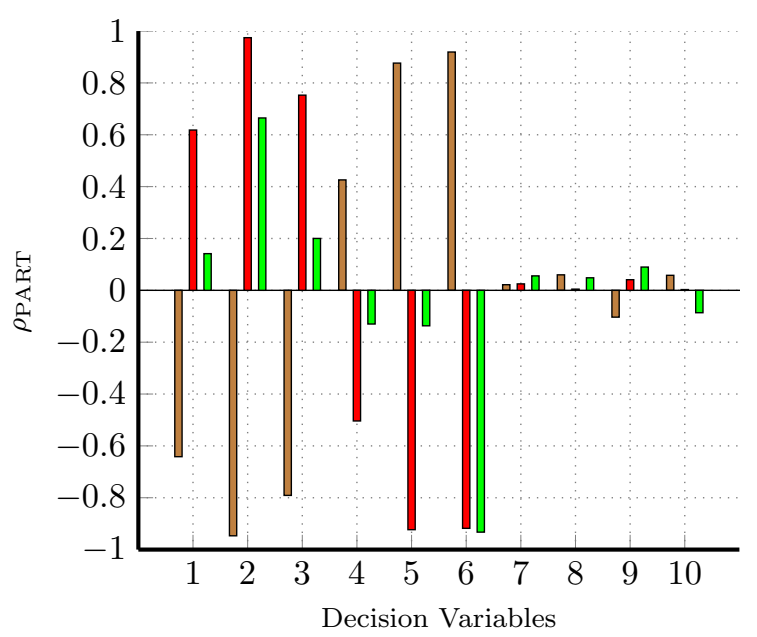

\begin{tabular}{llc}
\hline Number & Decision variable & Unit \\
\hline 1 & Condensation level & bar \\
2 & Vapour fraction (turbine outlet) & - \\
3 & Production level & bar \\
4 & Degree of superheating & $\mathrm{K}$ \\
5 & Load of the 1st gas turbine & - \\
6 & Load of the 2nd gas turbine & - \\
7 & Power share between the CC and the 2nd GT & - \\
8 & Rejection temperature of the process water & $\mathrm{K}$ \\
9 & Rejection temperature of the exhaust gases & $\mathrm{K}$ \\
10 & Rejection temperature of the additional seawater & $\mathrm{K}$ \\
\hline
\end{tabular}

Figure 10: Interdependencies between the master decision variables and optimisation objectives, characterised by the Pearson's partial correlation coefficients. Brown denotes the total investment costs, red the power capacity, and green the $\mathrm{CO}_{2}$-emissions. 
be explained by the larger amount of energy/exergy available for power production, and the selection of appropriate production and superheating levels becomes critical.

- the trends are overall similar for all clusters, and for all decision variables.

The distribution of the optimal values of the decision variables in the search spaces is given for the condensation and production levels, and for the vapour fraction at the turbine outlet (Figure 11). Most solutions located on the Pareto frontier are characterised by a value of the vapour fraction between 0.85 and 0.9. The colour shading illustrates that these solutions generally correspond to cases where the power capacity is maximised. These most optimal solutions are also featured by a steam production level at a pressure between 8 and 12 bar.
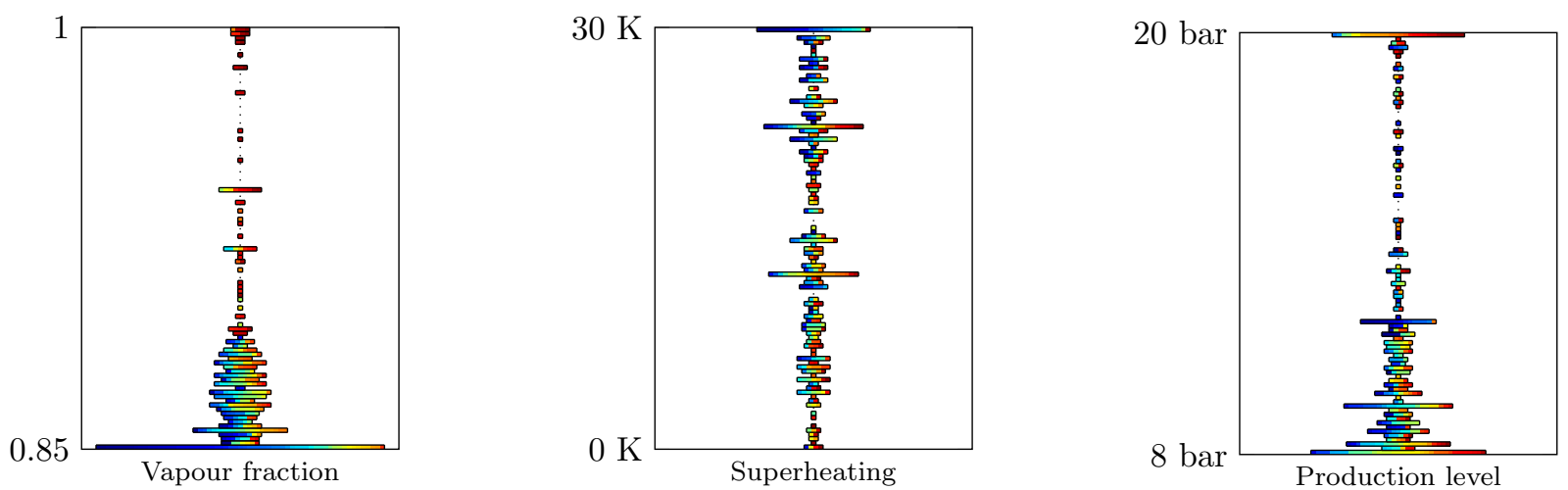

Figure 11: Selection of ranked variable distributions in the search space for Cluster 2 (waste heat recovery from the exhaust gases of 1 gas turbine and maintenance of the glycol loop), with respect to the maximum power capacity (blue $=$ maximum, red $=$ minimum .

The ranked variable distributions show that several technological (e.g. exhaust steam quality) and operational (e.g. power share between the combined cycle and the 2nd gas turbine) limitations impede the maximum power capacity. They illustrate the trade-off between minimising the total investment costs and maximising the thermodynamic efficiency of the power cycle. Some design choices, such as the degree of superheating, are uniformly spread in the search space, while others, such as the steam production level, are mainly concentrated in a restricted interval, without being severely conflictive.

\subsubsection{Thermoenvironomic penalties of the operational constraints}

In practice, there may be technological constraints on the selection of the cooling utility for the steam condensation. Moreover, the use of an intermediate glycol loop may be favoured for safety issues, and in some cases for heat buffering. Such a heating loop also increases the thermal losses of the system. Finally, the space and volume available on an offshore platform are limited, and the addition of a steam cycle may be both costly and problematic.

The penalty of each constraint can be illustrated by investigating the sensitivity of the Pareto frontiers (Figure 12). The optimal solutions derived in the ideal cases are compared to the solutions obtained when introducing an operational constraint in the system. The use of additional seawater, lifted and pumped onsite displays a clear penalty with regards to thermodynamic and economic aspects, with an average increase of $10 \%$ of the investment costs for the same net power capacity, and an average decrease of $20 \%$ of the net power capacity for the same investment expenses. These trends are confirmed and amplified if the steam cycle operates on the exhaust gases of two gas turbines.

These aspects are of particular importance if the space and allowable weight on the facility are limited. They are generally related to the number of equipments that should be added on-site, as well as to the power generation capacity of the process. 
A steam cycle using seawater presents the drawbacks of possibly requiring an additional lift pump and having a smaller power capacity for an equal investment expense. As expected, the glycol loop results in greater investment costs, because the steam cycle operates with a heat source at lower temperatures, and more waste heat needs to be recovered.
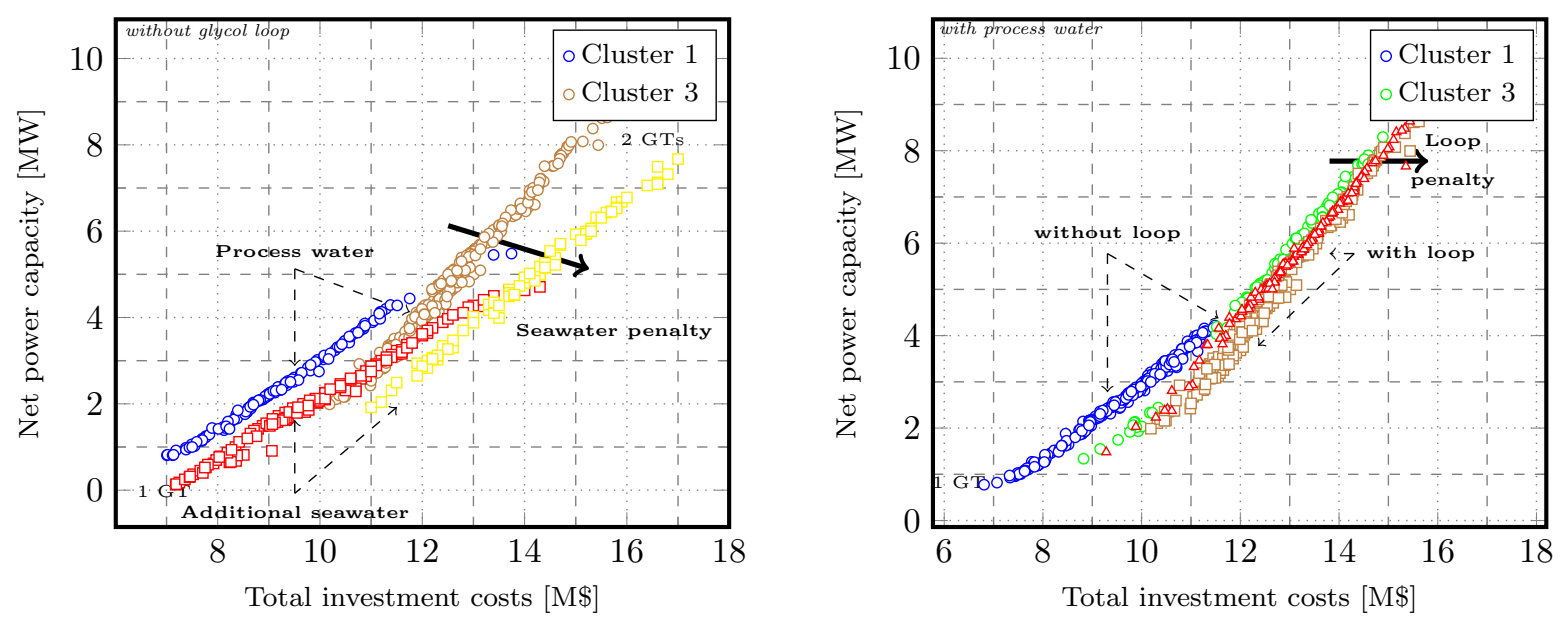

Figure 12: Evolution of the thermoeconomic Pareto-fronts with practical constraints: process water against seawater (left), with or without glycol intermediate loop (right).

The penalty of using seawater instead of process water is also depicted with regards to environmental aspects (Figure 13). Higher investment costs result in smaller $\mathrm{CO}_{2}$-emissions, and the difference between optimum cases with process water or seawater reaches up to 20 tonnes $\mathrm{CO}_{2}$ per day at low investment costs, and decreases to about 20 tonnes $\mathrm{CO}_{2}$ per day for investment costs greater than $14 \mathrm{M} \$$. The penalty related to the glycol loop is not significant in comparison.


Figure 13: Evolution of the thermoenvironomic Pareto-fronts with practical constraints: process water against seawater (left), with exhaust gases from one or two gas turbines (right).

Finally, using the glycol oil as heat buffer or heat source for the normal platform needs does not reduce significantly the performance of the steam cycle, as a smaller amount of waste heat can be recovered by the steam cycle (Figure 14). The maximum power capacity cannot exceed more than $7 \mathrm{MW}$, which corresponds to a total investment cost of $17 \mathrm{M} \$$. In comparison, a similar solution, in the original case, can be reached for an investment cost $15 \%$ lower. These differences in the economic performance of these cases are mainly 
related to the lower exhaust gas temperatures, and therefore to the higher heat transfer areas of the heat exchangers. Similarly, using exclusively seawater for the steam condensation is not promising, as the investment costs for the lift pumps and steam turbines increase, and the net power capacity of the steam cycle may decrease.
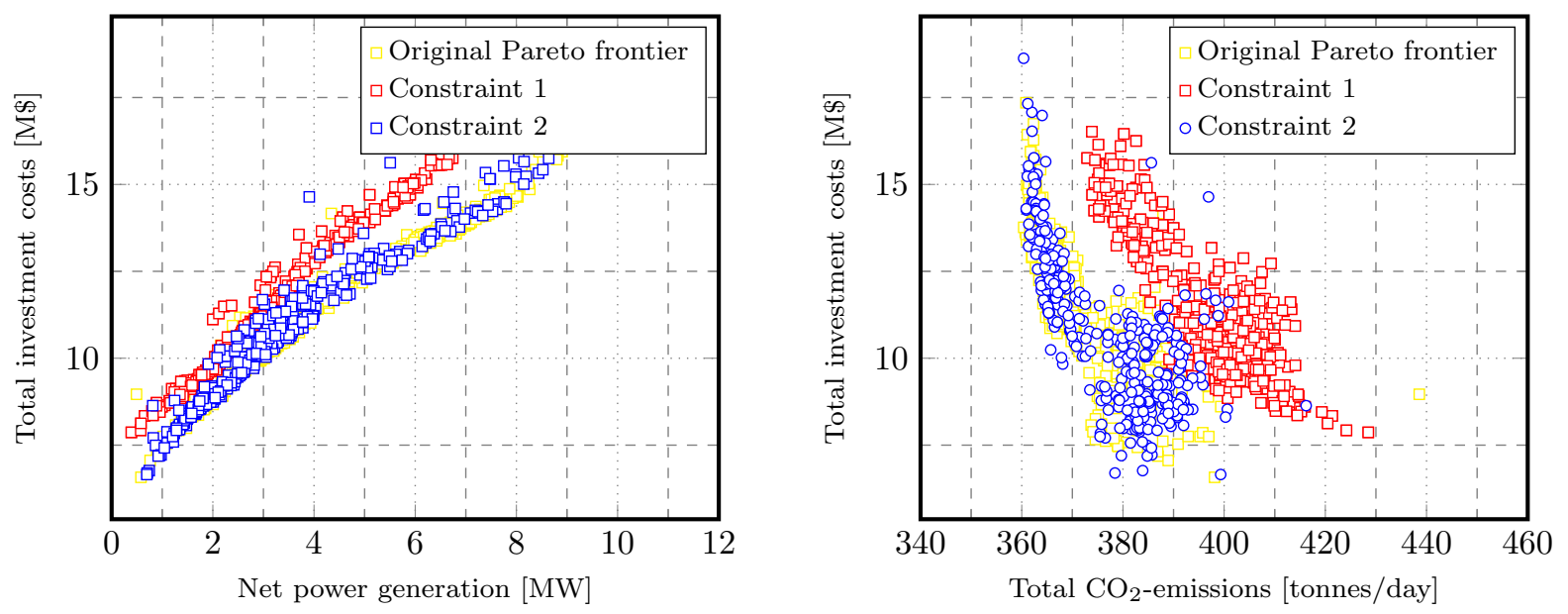

Figure 14: Constrained Pareto-optimal solutions for the site-scale integration of steam cycles on offshore platforms: original solution, seawater as cold source (constraint 1) and glycol as thermal buffer (constraint 2).

\section{Conclusions}

The site-scale integration of steam cycles on oil and gas platforms is evaluated with regards to their energy and exergy performances, their investment and operating costs, and their environmental impacts. The comparison of all potential configurations is conducted by combining a superstructure process model with process integration techniques and multi-objective optimisations. The trade-offs between conflicting objectives such as low investment costs, high fuel savings \& $\mathrm{CO}_{2}$-reductions, and high power generation capacity are assessed. The life cycle analysis highlights the significant $\mathrm{CO}_{2}$-emissions associated with the exhaust gases from the gas turbines and the small contributions from the process components, flaring practices and use of chemicals. The potential for an additional increase of the power generation capacity of the platform goes up to 8.5-9.5 MW, depending on the choice of the cold and hot utilities. Based on the assumptions made in this work, the investment costs vary in the range of 7-17 $\mathrm{M} \$$, while the $\mathrm{CO}_{2}$-emissions range between 260 and 350 tonnes per day, and between 0.04 and 0.06 ton per functional unit.

The most critical variables, which have a direct impact on the system configuration and performance, are namely the selection of the cooling utility, the use of an intermediate thermal loop, and the partial or total use of the exhaust gases. They affect simultaneously the investment costs, net power generation capacity, and $\mathrm{CO}_{2}$-emissions. They influence therefore the dispersion of the optimal thermoenvironomic solutions on the Pareto-frontiers.

In all cases, the integration of a steam cycles allows only a partial recovery of the waste heat and exergy contained in the flue gases and hot streams of the processing plant. The plant with the greatest power capacity displays a net power production of about $9.5 \mathrm{MW}$ for about 260 tonnes of carbon dioxide emitted per day. Substantial exergy pockets are found at temperatures as low as $20-80{ }^{\circ} \mathrm{C}$, and they can most likely be exploited by integrating a low-temperature power cycle.

In conclusion, the present paper supports the results of other works in this field, which promote the usefulness of applying advanced thermodynamic methods on petroleum processes. It also highlights the challenges in optimising systems, which, although similar in essence, present different operating conditions and strategies. We suggest to apply the present methodology to other and similar systems, and to take into consideration such results when analysing the integration of steam cycles on offshore platforms. 


\section{Acknowledgments}

The funding from the Norwegian Research Council through the Petromaks programme, within the project 2034/E30 led by Teknova is acknowledged.

\section{References}

[1] Manning, F.S., Thompson, R.E.. Oilfield processing of petroleum: Crude oil; vol. 2. Tulsa, USA: PennWell Books; 1991.

[2] Abdel-Aal, H.K., Aggour, M., Fahim, M.A.. Petroleum and Gas Field Processing. Chemical Industries; New York, USA: Marcel Dekker; 2003.

[3] Plisga, W.C.L., J., G., editors. Standard Handbook of Petroleum \& Natural Gas Engineering. Second ed.; Burlington, USA: Gulf Professional Publishing; 2004.

[4] Jones, D.S.J.S., Pujadó, P.R., editors. Handbook of Petroleum Processing. Dordrecht, The Netherlands: Springer; 2006.

[5] Bothamley, M.. Offshore Processing Options for Oil Platforms. In: Proceedings of the SPE Annual Technical Conference and Exhibition. Houston, USA: Society of Petroleum Engineers; 2004, p. 1-17 (Paper SPE 90325).

[6] Vanner, R.. Energy Use in Offshore Oil and Gas Production: Trends and Drivers for Efficiency from 1975 to 2025. PSI Working Paper; Policy Studies Institute; 2005.

[7] Stortinget, . Lov om petroleumsvirksomhet [petroleumsloven]. Tech. Rep. 72; OED (Olje- og energidepartementet); 1996.

[8] Statistisk Sentralbyrå, . Lavere klimagassutslipp i 2011. 2012. URL: www.ssb.no/emner/01/04/10/klimagassn/.

[9] Oljedirektoratet, . Nei til fakling - en internasjonal utfordring. 2008. URL: www.npd.no/no/Publikasjoner/Norsk-sokkel/ Nr2-2008/Nei-til-fakling/.

[10] Finansdepartementet, . Skatter og avgifter: green taxes. 2011. URL: www.regjeringen.no/nb/dep/fin/tema/skatter_ og_avgifter/green-taxes-2011.html?id=609076.

[11] Kloster, P.. Energy Optimization on Offshore Installations with Emphasis on Offshore and Combined Cycle Plants. In: Proceedings of the Offshore Europe Conference. Aberdeen, United Kingdom: Society of Petroleum Engineers; 1999, p. 1-9 (Paper SPE 56964).

[12] Kloster, P.. Reduction of Emissions to Air Through Energy Optimisation on Offshore Installations. In: Proceedings of the SPE International Conference on Health, Safety, and the Environment in Oil and Gas Exploration and Production. Stavanger, Norway: Society of Petroleum Engineers; 2000, p. 1-7 (Paper SPE 61651).

[13] Oliveira Jr., S.D., Van Hombeeck, M.. Exergy Analysis of Petroleum Separation Processes in Offshore Platforms. Energy Conversion and Management 1997;38(15-17):1577-1584.

[14] Nguyen, T.V., Pierobon, L., Elmegaard, B., Haglind, F., Breuhaus, P., Voldsund, M.. Exergetic assessment of energy systems on North Sea oil and gas platforms. Energy 2013;62:23-36.

[15] Voldsund, M., Ertesvåg, I.S., He, W., Kjelstrup, S.. Exergy Analysis of the Oil and Gas Processing a Real Production Day on a North Sea Oil Platform. Energy 2013;55:716-727.

[16] Nord, L.O., Bolland, O.. Steam bottoming cycles offshore - challenges and possibilities. Journal of Power Technologies 2013;92(3):201-207.

17] Nord, L.O., Bolland, O.. Design and off-design simulations of combined cycles for offshore oil and gas installations. Applied Thermal Engineering 2013;54:85-91.

[18] Walnum, H., Nekså, P., Nord, L., Andresen, T.. Modelling and simulation of $\mathrm{CO}_{2}$ (carbon dioxide) bottoming cycles for offshore oil and gas installations at design and off-design conditions. Energy 2013;59:513-520.

[19] Rohde, D., Walnum, H., Andresen, T., Nekså, P.. Heat recovery from export gas compression: Analyzing power cycles with detailed heat exchanger models. Applied Thermal Engineering 2013;60(1-2):1-6.

[20] Nguyen, T.V., Jacyno, T., Breuhaus, P., Voldsund, M., Elmegaard, B.. Thermodynamic analysis of an upstream petroleum plant operated on a mature field. Energy 2014;68:454-469.

[21] Norwegian Ministry of Petroleum and Energy, . Facts 2012 - The Norwegian Petroleum Sector. Tech. Rep.; Norwegian Petroleum Directorate; Oslo, Norway; 2012

[22] Pierobon, L., Kandepu, R., Haglind, F.. Waste Heat Recovery for Offshore Applications. In: Proceedings of the ASME 2012 International Mechanical Engineering Congress and Exposition; vol. 6: Energy, Parts A and B. ASME; 2012, p. 503-512.

[23] SIEMENS, . SGT-500 Industrial Gas Turbine. Tech. Rep.; Siemens Industrial Turbomachinery AB; Finnspong, Sweden; 2011.

[24] Li, K.J.. Use of Fractionation Column in an Offshore Environment. In: Proceedings of the SPE Annual Technical Conference and Exhibition. New Orleans, USA: Society of Petroleum Engineers; 1996, p. 1-11 (Paper SPE 49121).

[25] Maréchal, F., Kalitventzeff, B.. Targeting the optimal integration of steam networks: Mathematical tools and methodology. Computers and Chemical Engineering 1999;23(SUPPL. 1):S133-S136.

[26] Tock, L., Maréchal, F.. $\mathrm{H}_{2}$ processes with $\mathrm{CO}_{2}$ mitigation: Thermo-economic modeling and process integration. International Journal of Hydrogen Energy 2012;37(16):11785-11795.

[27] Gerber, L., Gassner, M., Maréchal, F.. Systematic integration of lca in process systems design: Application to combined fuel and electricity production from lignocellulosic biomass. Computers and Chemical Engineering 2011;35(7):1265-1280.

[28] Fazlollahi, S., Maréchal, F.. Multi-objective, multi-period optimization of biomass conversion technologies using evolutionary algorithms and mixed integer linear programming (milp). Applied Thermal Engineering 2013;50(2):1504-1513.

[29] Aspen Technology, . Aspen Plus - Modelling Petroleum Processes. Burlington, USA: Aspen Technology; 1999. 
[30] Peng, D.Y., Robinson, D.B.. A New Two-Constant Equation of State. Industrial \& Engineering Chemistry Fundamentals 1976;15(1):59-64

[31] Schwartzentruber, J., Renon, H.. Extension of UNIFAC to High Pressures and Temperatures by the Use of a Cubic Equation of State. Industrial \& Engineering Chemistry Research 1989;28(7):1049-1055.

[32] Schwartzentruber, J., Renon, H., Watanasiri, S.. Development of a new cubic equation of state for phase equilibrium calculations. Fluid Phase Equilibria 1989;52:127-134.

[33] Elmegaard, B., Houbak, N.. DNA - A General Energy System Simulation Tool. In: Amundsen, J., editor. Proceedings of SIMS 2005 - 46th Conference on Simulation and Modeling. Trondheim, Norway: Tapir Academic Press; 2005 , p. 43-52.

[34] Song, T.W., Kim, T.S., Kim, J.H., Ro, S.T.. Performance prediction of axial flow compressors using stage characteristics and simultaneous calculation of interstage parameters. In: Proceedings of the Institution of Mechanical Engineers; vol. 215 Part A. London, United Kingdom: Institution of Mechanical Engineers; 2001, p. 89-98.

[35] Muir, D.E., Saravanamuttoo, H.I.H., Marshall, D.J.. Health Monitoring of Variable Geometry Gas Turbines for the Canadian Navy. ASME Journal of Engineering for Gas Turbines and Power 1989;111(2):244-250.

[36] Spina, P.R.. Gas Turbine performance prediction by using generalized performance curves of compressor and turbine stages. In: Proceedings of the ASME Turbo Expo 2002: Power for Land, Sea, and Air (GT2002); vol. 2. Amsterdam, The Netherlands; 2002, p. 1073-1082.

[37] Templalexis, I., Pilidis, P., Pachidis, V., Kotsiopoulos, P.. Development of a two-dimensional streamline curvature code. ASME Journal of Turbomachinery 2011;133(1):011003.

[38] Lieblein, S.. Analysis of experimental low-speed loss and stall characteristics of two-dimensional compressor blade cascades. Washington, USA: NACA RM E57A28; 1957.

[39] Saravanamuttoo, H.I.H., Rogers, G.F.C., Cohen, H., Straznicky, P.. Gas Turbine Theory. Sixth ed.; Upper Saddle River, USA: Pearson Prentice Hall; 2008.

[40] Stodola, A.. Dampf- und Gasturbinen. Sixth ed.; Berlin, Germany: Springer; 1924.

[41] Traupel, W.. Thermische Turbomaschinen. Third ed.; Berlin, Germany: Springer; 1977.

[42] Maréchal, F., Kalitventzeff, B.. Energy integration of industrial sites: Tools, methodology and application. Applied Thermal Engineering 1998;18(11):921-933.

[43] Marechal, F., Kalitventzeff, B.. Targeting the minimum cost of energy requirements: A new graphical technique for evaluating the integration of utility systems. Computers and Chemical Engineering 1996;20(SUPPL.1):S225-S230.

[44] Turton, R., Bailie, R., Whiting, W., Shaeiwitz, J., Bhattacharyya, D.. Analysis, Synthesis and Design of Chemical Processes. Prentice Hall International Series in the Physical and Chemical Engineering Sciences; 4th ed.; Prentice Hall; 2012.

[45] Swiss Centre for Life Cycle Inventories, . Ecoinvent. 2013. URL: www.ecoinvent.org.

[46] Leyland, G.. Multi-objective optimisation applied to industrial energy problems. Ph.D. thesis; École Polytechnique Fédérale de Lausanne; 2002.

[47] Molyneaux, A.. A practical evolutionary method for the multi-objective optimisation of complex integrated energy systems including vehicle drivetrains. Ph.D. thesis; École Polytechnique Fédérale de Lausanne; 2002.

[48] Mattson, C., Messac, A.. Pareto Frontier Based Concept Selection under Uncertainty, with Visualization. OPTE: Optimization and Engineering 2005;6(1):85-115.

[49] Svalheim, S.M.. Environmental Regulations and Measures on the Norwegian Continental Shelf. In: Proceedings of the SPE International Conference on Health, Safety and Environment in Oil and Gas Exploration and Production. Kuala Lumpur, Malaysia: Society of Petroleum Engineers; 2002, p. 1-10 (Paper SPE 73982).

[50] Pearson, K.. Note on Regression and Inheritance in the Case of Two Parents. Proceedings of the Royal Society of London $1895 ; 58: 240-242$.

[51] Kendall, M., Stuart, A.. The Advanced Theory of Statistics, Vol.2: Inference and Relationship. Charles Griffin; 1961.

\section{Appendix A. Composite curves}

\section{Appendix B. Pareto frontiers}



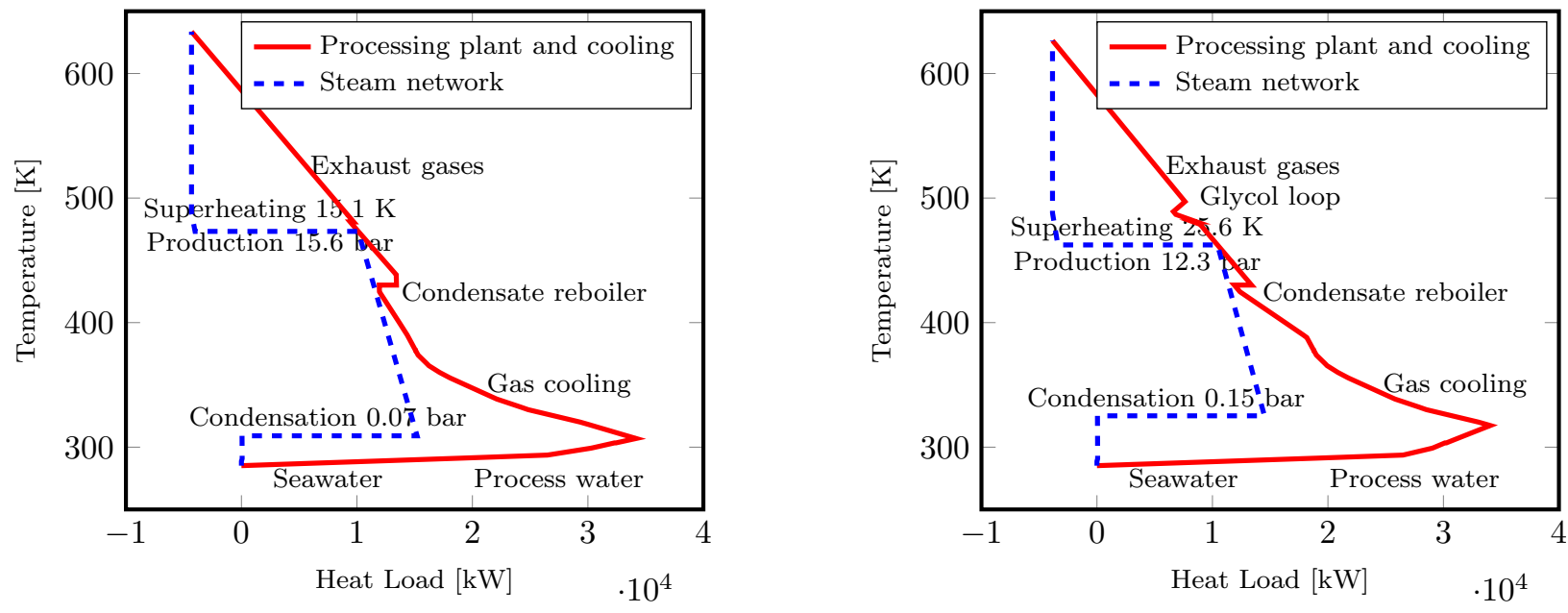

Figure A.15: Integrated Composite Curves (ICC) of the Steam network for an optimum case of Cluster 1 (Configuration A) and of Cluster 2 (Configuration B)
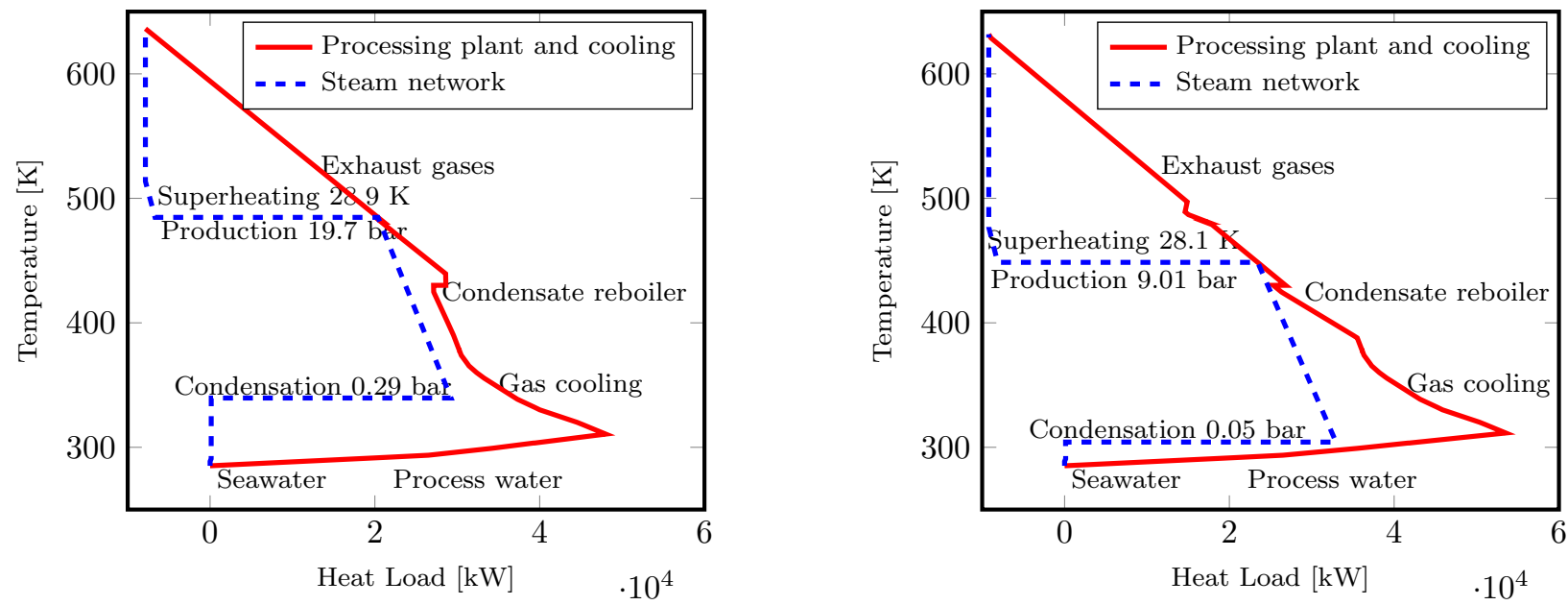

Figure A.16: Integrated Composite Curves (ICC) of the Steam network for an optimum case of Cluster 3 (Configuration C) and of Cluster 4 (Configuration D) 

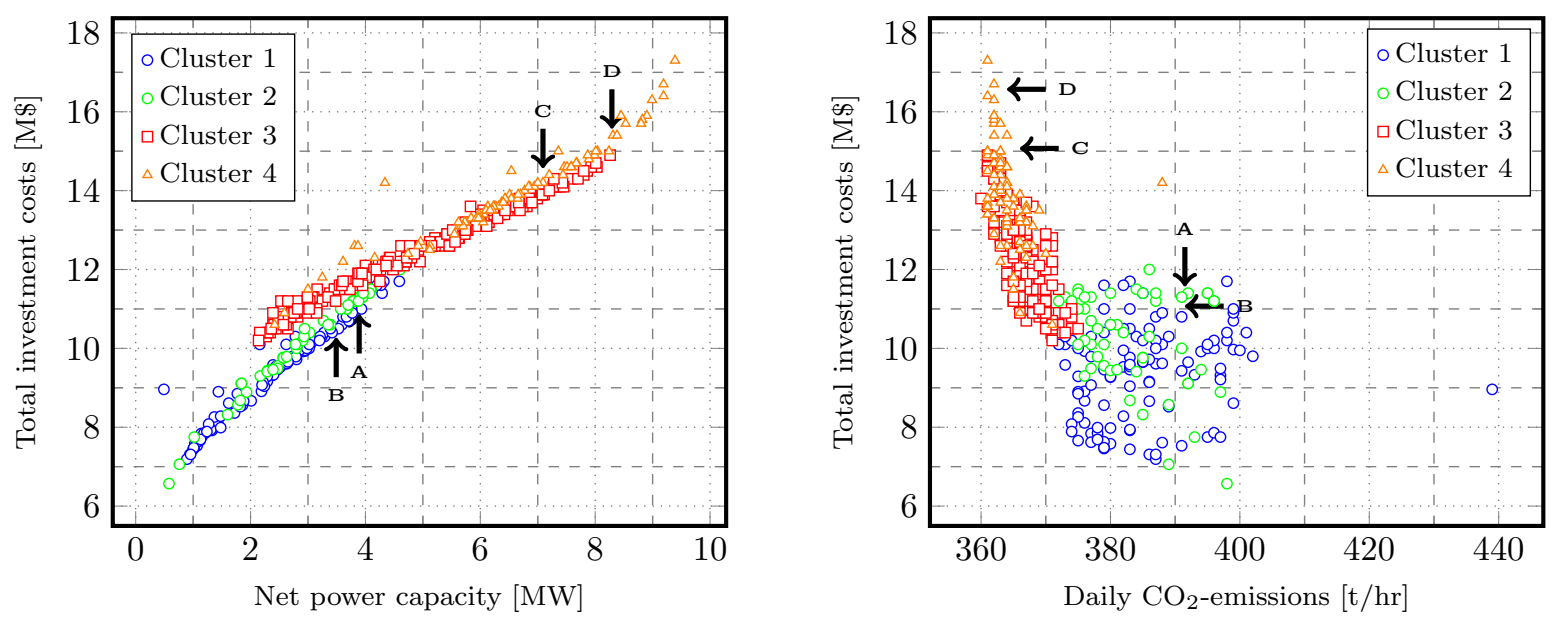

Figure B.17: Pareto-optimal solutions for the site-scale integration of steam cycles on offshore platforms: thermoeconomic and thermoenvironomic solutions. 